\title{
The libRadtran software package for radiative transfer calculations (version 2.0.1)
}

\author{
Claudia Emde ${ }^{1}$, Robert Buras-Schnell ${ }^{5}$, Arve Kylling ${ }^{2}$, Bernhard Mayer $^{1}$, Josef Gasteiger $^{1}$, Ulrich Hamann $^{4}$, \\ Jonas Kylling $^{2,3}$, Bettina Richter ${ }^{1}$, Christian Pause ${ }^{1}$, Timothy Dowling ${ }^{6}$, and Luca Bugliaro ${ }^{7}$ \\ ${ }^{1}$ Meteorological Institute, Ludwig-Maximilians-University, Theresienstr. 37, 80333 Munich, Germany \\ ${ }^{2}$ NILU - Norwegian Institute for Air Research, Kjeller, Norway \\ ${ }^{3}$ Department of Mathematics, Faculty of Mathematics and Natural Sciences, University of Oslo, Oslo, Norway \\ ${ }^{4}$ MeteoSwiss, Radar, Satellite and Nowcasting Division, Via ai Monti 146, Locarno, Switzerland \\ ${ }^{5}$ Schnell Algorithms, Am Erdäpfelgarten 1, 82205 Gilching, Germany \\ ${ }^{6}$ Dept. of Physics \& Astronomy, University of Louisville, Louisville, KY 40292, USA \\ ${ }^{7}$ Institut für Physik der Atmosphäre, Deutsches Zentrum für Luft- und Raumfahrt (DLR), Oberpfaffenhofen, \\ 82234 Wessling, Germany
}

Correspondence to: Claudia Emde (claudia.emde@lmu.de)

Received: 24 August 2015 - Published in Geosci. Model Dev. Discuss.: 2 December 2015

Revised: 12 April 2016 - Accepted: 14 April 2016 - Published: 3 May 2016

\begin{abstract}
Radtran is a widely used software package for radiative transfer calculations. It allows one to compute (polarized) radiances, irradiance, and actinic fluxes in the solar and thermal spectral regions. libRadtran has been used for various applications, including remote sensing of clouds, aerosols and trace gases in the Earth's atmosphere, climate studies, e.g., for the calculation of radiative forcing due to different atmospheric components, for UV forecasting, the calculation of photolysis frequencies, and for remote sensing of other planets in our solar system. The package has been described in Mayer and Kylling (2005). Since then several new features have been included, for example polarization, Raman scattering, a new molecular gas absorption parameterization, and several new parameterizations of cloud and aerosol optical properties. Furthermore, a graphical user interface is now available, which greatly simplifies the usage of the model, especially for new users. This paper gives an overview of libRadtran version 2.0.1 with a focus on new features. Applications including these new features are provided as examples of use. A complete description of libRadtran and all its input options is given in the user manual included in the libRadtran software package, which is freely available at http://www.libradtran.org.
\end{abstract}

\section{Introduction}

Radiative transfer modelling is essential not only for remote sensing of planetary atmospheres, but also for many other fields in atmospheric physics: atmospheric chemistry, which is largely influenced by photochemical reactions, calculation of radiative forcing in climate models, and radiatively driven dynamics in numerical weather prediction models.

The libRadtran software package is a versatile toolbox, which has been used for various applications related to atmospheric radiation, a list of publications that have used the package can be found on the website http://www.libradtran. org; currently it includes more than 400 entries. Applications include the following topics (the given references are taken as examples out of the list of publications):

- analysis of $U V$-radiation measurements, from which parameters, e.g. ozone concentrations, aerosol optical thickness, UV-index, are derived. Since the libRadtran package originally was a radiative transfer code for the UV spectral range (the main executable is still called uvspec), the model is well established in this research area and frequently used (e.g. Seckmeyer et al., 2008; Kreuter et al., 2014); 
- cloud and aerosol remote sensing using measurements in solar and thermal spectral regions. The developed retrieval methods are for ground-based, satellite and airborne instruments that measure (polarized) radiances (e.g. Painemal and Zuidema, 2011; Bugliaro et al., 2011; Zinner et al., 2010; Alexandrov et al., 2012);

- volcanic ash studies including remote sensing of ash mass concentrations (e.g. Gasteiger et al., 2011; Kylling et al., 2015) and visibility of ash particles from the pilot's perspective (e.g. Weinzierl et al., 2012);

- remote sensing of surface properties: a model like libRadtran is particularly important to develop atmospheric correction methods (e.g. Drusch et al., 2012; Schulmann et al., 2015);

- trace gas remote sensing: libRadtran used as a forward model for retrievals of $\mathrm{O}_{3}, \mathrm{NO}_{2}$, and $\mathrm{BrO}$ from DOAS (Differential Optical Absorption Spectroscopy) measurements (e.g. Theys et al., 2007; Emde et al., 2011);

- calculation of actinic fluxes in order to quantify photolysis rates for atmospheric chemistry (e.g. SuminskaEbersoldt et al., 2012);

- determination of solar direct irradiance and global irradiance distributions in order to optimize locations of solar energy platforms (e.g. Lohmann et al., 2006) and calculation of circumsolar irradiance (Reinhardt et al., 2014);

- simulation of satellite radiances to be used for data assimilation in numerical weather prediction models (Kostka et al., 2014);

- validation of radiation schemes included in climate models (Forster et al., 2011), calculation of radiative forcing of clouds and contrail cirrus (Forster et al., 2012), impacts of aviation on climate (e.g. Lee et al., 2010);

- simulation of heating rates in three-dimensional (3-D) atmospheres to develop fast radiation parameterizations for large eddy simulation (LES) models (Klinger and Mayer, 2014);

- simulation of solar radiation during a total eclipse (Emde and Mayer, 2007);

- rotational Raman scattering explaining the filling-in of Fraunhofer lines in the solar spectrum (Kylling et al., 2011);

- Estimation of background radiation affecting lidar measurements (e.g. Ehret et al., 2008);
- Remote sensing of planetary atmospheres (e.g. Rannou et al., 2010).

Since the publication of the first libRadtran reference paper (Mayer and Kylling, 2005), the model has been further developed. It includes numerous new features that will be the focus of this paper.

One of the major extensions is the implementation of polarization in the radiative transfer solver MYSTIC (Monte Carlo code for the phYSically correct Tracing of photons In Cloudy atmospheres) (Emde et al., 2010), which is important because an increasing number of polarimetric observations have been performed during the last years and are planned for the future, from ground, satellite, and aircraft. These observations include more information about optical and microphysical properties of atmospheric particles than total radiances alone (Kokhanovsky et al., 2010b; Mishchenko et al., 2007). Another important reason for considering polarization is that in the shortwave spectral region (below about $500 \mathrm{~nm}$ ), the neglect of polarization can lead to large errors: more than $10 \%$ for a molecular atmosphere and up to $5 \%$ for an atmosphere with aerosol (Mishchenko et al., 1994; Kotchenova et al., 2006).

Moreover libRadtran now includes a solver to calculate rotational Raman scattering (Kylling et al., 2011), which improves the accuracy of trace gas retrievals. Further the Raman-scattering signal can be used to estimate cloud top pressure from satellite measurements and aerosol properties from surface and satellite observations.

Numerous state-of-the-art parameterizations for aerosol and ice cloud optical properties have been included (see Sects. 5 and 6). These new parameterizations provide more accurate radiance calculations. In particular for polarized radiative transfer, which requires not only the scattering phase function but the full scattering phase matrix, new data on optical properties were required. In order to improve the accuracy for highly peaked phase functions - which are typical for ice clouds - an improved intensity correction method has been developed and included into the DISORT solver (Buras et al., 2011), and new variance reduction methods have been developed for the Monte Carlo solver MYSTIC (Buras and Mayer, 2011). libRadtran has also been rewritten to allow for simulations with an arbitrary number of cloud and aerosol types - which can, e.g., be used to take into account detailed particle size distributions (number densities for discretized size bins) that can be different in each layer. In earlier versions it was only possible to take into account parameterized size distributions such as gamma or log-normal distributions.

A new gas absorption parameterization for the solar and thermal spectral ranges has been developed (Gasteiger et al., 2014). It is available in different spectral resolutions and can be applied for the simulation of radiances and irradiance. It is particularly useful for efficient simulations of radiances measured by satellite instruments (see Sect. 4.1). 
The DISORT radiative transfer solver has been translated from FORTRAN77 to the $\mathrm{C}$ programming language. All variables were transferred from single to double precision. These changes improved the numerical stability of the code and reduced computational time significantly (for details see Buras et al., 2011).

The paper is organized as follows: Sect. 2 provides an overview of the uvspec radiative transfer model, which is the core of the libRadtran package. Section 3 gives a short description of the radiative transfer solvers included in uvspec. Section 4 provides a summary of how molecules are handled and outlines various ways to include molecular absorption. Moreover, Rayleigh-scattering parameterizations are described. Section 5 summarizes the available parameterizations for aerosol microphysical and optical properties. Section 6 gives an overview of the parameterizations for water and ice clouds and also outlines how these were generated. In Sect. 7 available surface properties are described, including Lambertian reflection, bi-directional distribution functions and fluorescent surfaces. In Sect. 8 we describe code and implementation improvements relevant for users. Section 9 introduces the graphical user interface for uvspec. Section 10 provides a short summary of additional tools that come with the libRadtran package. Finally, Sect. 11 shows a few applications as examples of the usage of libRadtran.

\section{The uvspec radiative transfer model}

The main tool of the libRadtran package is the uvspec radiative transfer model, which consists of the following parts:

1. The atmospheric state (e.g. trace gas profiles, cloud liquid water content, cloud droplet size, aerosol concentration profiles) needs to be provided as input to the model.

2. The user may select between various parameterizations to convert the atmospheric state into optical properties, e.g. to convert from cloud liquid water content and effective droplet size to extinction coefficient, single-scattering albedo, and scattering phase function, or phase matrix when polarization is considered.

3. The optical properties are passed to a radiative transfer equation (RTE) solver, where again it is up to the user to select the most appropriate one for the given application. Currently, more than a dozen different solvers are included in uvspec. The six most used and maintained RTE solvers are listed in Table 1 and briefly described in Sect. 3. Among them are relatively simple and fast twostream solvers to compute irradiance, the widely used discrete ordinate solver DISORT and also the Monte Carlo solver MYSTIC to compute (polarized) radiances or irradiance in 3-D geometry.

4. The output of the RTE solver are radiation quantities as irradiance, actinic flux, or (polarized) radiance. The

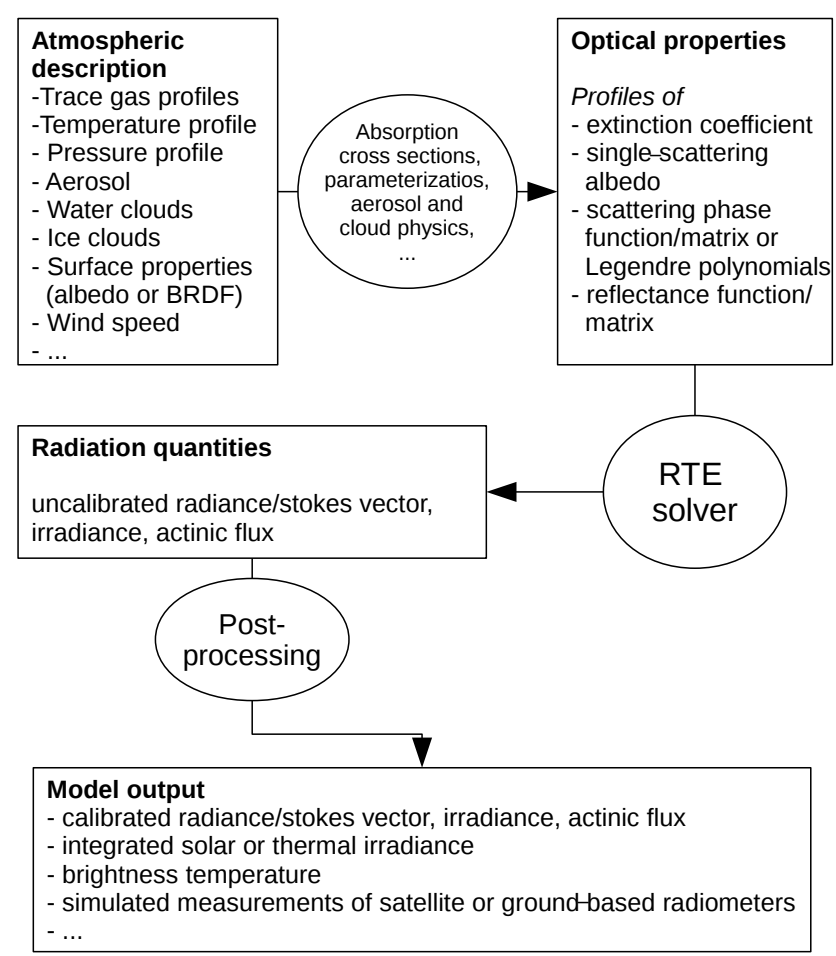

Figure 1. Structure of the uvspec radiative transfer model.

quantities are normalized to the source function, i.e. the solar irradiance in the solar spectral region. In order to get physical quantities with corresponding units the output may be post-processed. The uvspec output then corresponds to calibrated radiances or brightness temperatures for a given instrumental filter function. It is also possible to obtain integrated solar or thermal irradiance.

The overall structure of the uvspec model is shown in Fig. 1.

The model was originally designed to compute UV radiation; therefore, its name is uvspec. As said before it now covers the complete solar and thermal spectral range.

The usage of the model is described in the user guide, which comes along with the package. The user guide includes descriptions of the RTE solvers, examples of use as well as detailed documentation of all options and respective parameters. Below uvspec input options are put in teletypefont, for example rte_solver.

The uvspec model may be run either from the command line using

uvspec < input_file > output_file

or from the graphical user interface (see Sect. 9).

\section{Radiative transfer equation solvers}

The RTE for a macroscopically isotropic medium, i.e. randomly oriented particles and molecules, may be written as 
Table 1. The radiative transfer equation solvers currently implemented in libRadtran.

\begin{tabular}{|c|c|c|c|c|}
\hline $\begin{array}{l}\text { RTE } \\
\text { solver }\end{array}$ & Geometry & $\begin{array}{l}\text { Radiation } \\
\text { quantities }\end{array}$ & References & Method \\
\hline disort & 1-D, PP, PS & $E, F, L$ & $\begin{array}{l}\text { Stamnes et al. (1988, 2000); Buras et al. (2011); } \\
\text { Dahlback and Stamnes (1991) }\end{array}$ & discrete ordinate, $\mathrm{C}$-version \\
\hline mystic & 1-D, 3-D ${ }^{\mathrm{a}}, \mathrm{PP}, \mathrm{SP}$ & $E, F, L, \mathbf{I}$ & $\begin{array}{l}\text { Mayer (2009); Emde and Mayer (2007); Emde } \\
\text { et al. (2010); Mayer et al. (2010); Buras and } \\
\text { Mayer (2011); Emde et al. (2011); Klinger and } \\
\text { Mayer (2014) }\end{array}$ & Monte Carlo \\
\hline twostr & 1-D, PS & $E, F$ & Kylling et al. (1995) & two-stream, \\
\hline rodents & 1-D, PP & E & Zdunkowski et al. (2007) & $\begin{array}{l}\text { two-stream, } \\
\text { plane-parallel }\end{array}$ \\
\hline sslidar & 1-D, PP & $*$ & & single-scattering lidar \\
\hline tzs & 1-D, PP & $L(\mathrm{TOA})$ & & thermal, zero scattering \\
\hline
\end{tabular}

a 3-D version not included in the free package; available in joint projects.

Explanation: PP, plane-parallel; PS, pseudo-spherical; SP, fully spherical; 1-D, one-dimensional; 3-D, three-dimensional; $*$ sslidar: see Sect. 3.4 ; $E$, irradiance; $F$, actinic flux; $L$, radiance; $L$ (TOA), radiance at top of atmosphere; $\mathbf{I}$ is the Stokes vector (polarized radiance).

(Chandrasekhar, 1950; Mishchenko et al., 2002)

$\frac{\mathrm{d} \mathbf{I}}{\beta \mathrm{d} s}=-\mathbf{I}+\mathbf{J}$,

where the source function $\mathbf{J}$ is

$\mathbf{J}=\frac{\omega_{0}}{4 \pi} \int \mathbf{P}\left(\boldsymbol{\Omega}, \boldsymbol{\Omega}^{\prime}\right) \mathbf{I}\left(\boldsymbol{\Omega}^{\prime}\right) \mathrm{d} \boldsymbol{\Omega}^{\prime}+\left(1-\omega_{0}\right) \mathbf{B}_{\mathrm{e}}(T)$.

Here $\mathbf{I}=(I, Q, U, V)$ is the Stokes vector at location $(x, y, z), \beta$ the volume extinction coefficient, $\omega_{0}$ the singlescattering albedo, $\mathbf{P}\left(\boldsymbol{\Omega}, \boldsymbol{\Omega}^{\prime}\right)$ the scattering phase matrix, and $\mathbf{B}_{\mathrm{e}}(T)=(B(T), 0,0,0)$ the emission vector including the Planck function $B(T)$. For most applications in the Earth's atmosphere, thermal emission can be neglected for wavelengths below about $3 \mu \mathrm{m}$. Polarization is also often neglected, in this case the Stokes vector in Eqs. (1) and (2) is replaced by the radiance $L$, the phase matrix becomes the scalar phase function $p\left(\boldsymbol{\Omega}, \boldsymbol{\Omega}^{\prime}\right)$ and the emission vector is just the Planck function $B(T)$.

The uvspec model includes various methods to solve Eq. (1). The list of solvers, which may be selected using the option rte_solver, is shown in Table 1 .

\subsection{DISORT}

The solver disort is used by default in libRadtran. DISORT (Stamnes et al., 2000) is based on discrete ordinates and allows one to compute radiances, irradiance, and actinic fluxes in plane-parallel geometry. The original FORTRAN77 version of the algorithm exhibited several numerical instabilities for certain combinations of geometries and optical properties. The FORTRAN77 code has been translated to C-code and is entirely in double precision (the FORTRAN77 version is mostly in single precision) and includes dynamic memory allocation (not possible in FORTRAN77). As such, the C version is numerically stable and also faster than the original
FORTRAN77 version. We thus use the $\mathrm{C}$ version of the DISORT algorithm by default. The original FORTRAN77 version may still be invoked by fdisort2. Both the C-code and the FORTRAN77 version include the new intensity correction method for peaked phase functions by Buras et al. (2011), which is used by default.

For calculations with rotational Raman scattering, the $\mathrm{C}$ version has been generalized so that arbitrary source functions (not only a solar or thermal source function) can be handled (Kylling and Stamnes, 1992; Kylling et al., 2011). Rotational (inelastic) Raman scattering from other wavelengths into the wavelength, for which the RTE is solved, is included into the source term.

\subsection{MYSTIC}

The most comprehensive solver in libRadtran is the Monte Carlo model MYSTIC (Mayer, 2009), which may be used to calculate (polarized) radiances, irradiance, and actinic fluxes in the solar and thermal spectral regions. Within MYSTIC photons are traced through the atmosphere from the source towards the sensor or backwards, from the sensor to the source, which is much more efficient especially in the thermal wavelength region. One of the main applications of MYSTIC is to calculate radiances in cloudy atmospheres. The sharp forward scattering of clouds and aerosols causes numerical problems in Monte Carlo models. In order to avoid these, sophisticated variance reduction methods have been developed (Buras and Mayer, 2011). These are enabled using mc_vroom on. Solar radiation is initially unpolarized and becomes polarized by molecular, aerosol, or cloud scattering in the atmosphere. With the option mc_polarisation (Emde et al., 2010), the full Stokes vector is calculated. For 1-D atmospheres, MYSTIC may also be operated in spherical geometry using the option mc_spherical (Emde and Mayer, 2007). 
The public version of MYSTIC allows for calculations in 1-D (plane-parallel or spherical) geometry. A full 3-D version is also available for joint projects. The non-public version includes several other features: complex 3-D topography (Mayer et al., 2010) and efficient high-spectralresolution calculations using absorption lines importance sampling (Emde et al., 2011).

\subsection{Two-stream solvers}

For the calculation of irradiance, two fast two-stream solvers are available.

The first solver, twost $r$, is described in detail in Kylling et al. (1995). twostr is optimized for calculating actinic fluxes, and hence heating rates. It can be run in plane parallel as well as in pseudo-spherical geometry.

The second two-stream method available in libRadtran is rodents, which is based on the delta-Eddington two stream described, e.g., in Zdunkowski et al. (2007), Sects. 6.1-6.4 ${ }^{1}$. Based on a different two-stream approach than twostr, it naturally yields different results. In contrast to twost $r$, neither the pseudo-spherical approximation is implemented nor is rodents capable of calculating actinic fluxes.

For actinic fluxes and atmospheric heating rates, twostr is the better choice. However, for calculating solar irradiance, we recommend using rodents: for cases where the resulting irradiance is not negligible (larger than $2 \%$ of the extraterrestrial irradiance), the difference between rodents and exact disort calculations is on average $5 \%$ (7\%) for down(up)-welling irradiance. For twostr the values are $9 \%(11 \%)$. Especially in case the atmosphere is only weakly absorbing, the average differences at top-ofatmosphere (TOA) and at the surface are only $2 \%(1 \%)$ for rodents, whereas they are $5 \%$ at TOA and even $13 \%$ $(18 \%)$ at surface for twostr.

For the thermal irradiance, rodents also gives better results at TOA $(1.6 \%)$ and at the surface $(1 \%)$ than twostr (3\%). For irradiance within the atmosphere, no real preference can be given.

\subsection{Lidar and radar simulations}

In order to complement the instruments that can be simulated by libRadtran, a lidar simulator called sslidar has been implemented. It only takes into account single scattering and reflection and is based on the lidar equation, which is integrated over each range. Note that in order to obtain a smooth signal, a fine vertical resolution of the model atmosphere is required. The vertical resolution should correspond

\footnotetext{
${ }^{1}$ Note that Zdunkowski et al. (2007) contains two misprints relevant for the two-stream solver: first, in Eq. (6.50), $\alpha_{12 \text {,Ed }=}$ $-\alpha_{21, \mathrm{Ed}}$ and $\alpha_{22, \mathrm{Ed}}=-\alpha_{11, \mathrm{Ed} .}$ Second, $\alpha_{2}^{2}$ in Eq. (6.88) should be $\alpha_{2}$. Also, the derivation in Sect. 6.5 for thermal radiation does not work, instead the equations need to be derived in analogy to the solar radiation.
}

to the range width of the simulated lidar instrument. For radar simulations a stand-alone tool is available (see Sect. 10.2).

\subsection{Other solvers}

The solver tzs (see Appendix B) is based on the zeroscattering approximation in the thermal spectral range. It may be used for clear-sky calculations of radiances at TOA. It also calculates "black cloud" radiances for the application of the $\mathrm{CO}_{2}$-slicing algorithm (Smith et al., 1970; Chahine, 1974; Smith and Platt, 1978; Menzel et al., 1983; Eyre and Menzel, 1989), which may be used for the determination of cloud top temperatures from passive remote sensing measurements in the thermal spectral range.

For the solar region a fast single-scattering solver ss is available. These solvers may be used for fast but approximate simulations of satellite measurements.

Several other RTE solvers are included in uvspec for compatibility with earlier releases of the package. These include sdisort (pseudospherical disort), spsdisort (single precision, pseudospherical disort), fdisort 1 (version 1 of DISORT), and polradtran (Evans and Stephens, 1991). While they may still be used, we do not recommend their use as the other solvers listed in Table 1 perform better.

\subsection{Accuracy of solvers}

The MYSTIC model has been validated in many international model intercomparison studies, for radiance calculations with highly peaked phase functions (Kokhanovsky et al., 2010a), for polarized radiance calculations (Emde et al., 2015), and for radiances and irradiance in 3-D model domains (Cahalan et al., 2005). In all studies MYSTIC belongs to the core of models that produce equal results within their uncertainty range. MYSTIC agrees perfectly with DISORT for radiances and irradiance with only a few exceptions, e.g. for circum-solar radiation, where the second-order intensity correction included in DISORT is not accurate enough for highly peaked scattering phase functions (Buras et al., 2011). In Emde et al. (2011), a comparison between DISORT and MYSTIC for a radiance spectrum in the $\mathrm{O}_{2}-\mathrm{A}$ band is shown. The relative difference between the solvers is less than $0.05 \%$ here. All other solvers are approximations and hence less accurate: as mentioned before the two-stream solvers are only appropriate for irradiance and the $t$ z s solver only provides radiances in thermal atmospheres and neglects scattering completely.

The accuracy of MYSTIC depends only on the number of traced photons. The standard deviation of MYSTIC is calculated when the option mc_std is enabled. The user may run MYSTIC with many photons as reference for some cases in order to check the accuracy of other solvers for specific applications. 

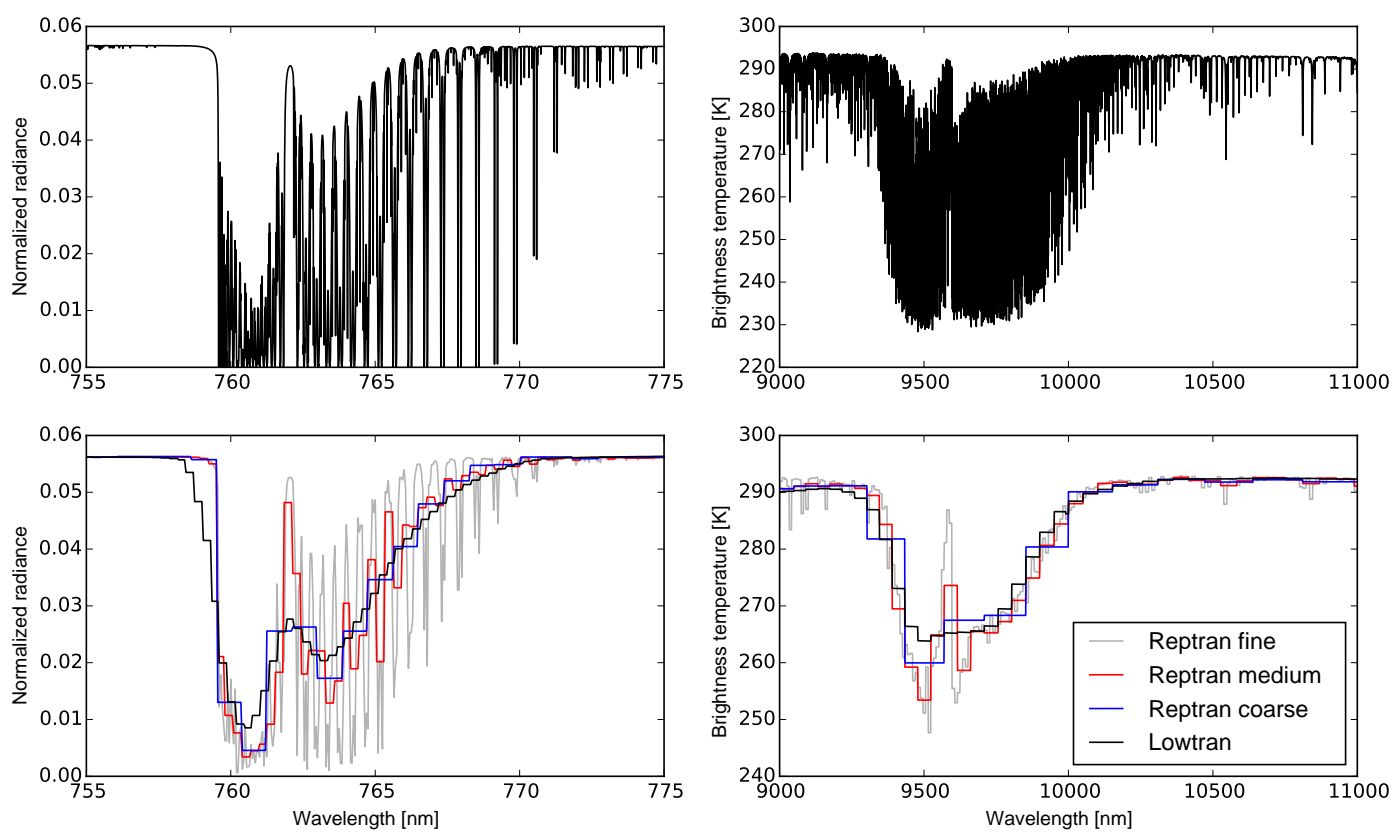

Figure 2. Nadir top-of-the-atmosphere radiance in the oxygen-A band around $760 \mathrm{~nm}$ (left) and in the IR (infra-red) window region (right) for the midlatitude-summer atmosphere of Anderson et al. (1986). All calculations were performed with the MYSTIC solver using the "absorption lines importance sampling" method (Emde et al., 2011). (Top) high spectral resolution calculation, based on line-by-line absorption cross sections calculated using ARTS (Eriksson et al., 2011); (bottom) pseudo-spectral calculations using the representative wavelengths band parameterizations (reptran) with different resolutions and lowtran. For comparison see also Fig. 3 in Mayer and Kylling (2005), which shows transmittances for genln2 line-by-line calculations and lowtran for the same spectral regions.

\section{Molecules}

\subsection{Molecular absorption parameterizations}

Spectral ranges affected by molecular absorption comprising a complex line structure require parameterizations to reduce the computational cost. Molecular absorption parameterizations included in libRadtran are listed in Table 2. By default the reptran parameterization is applied. Using the option mol_abs_param, the user may select the most appropriate parameterization for the specific application. As an example Fig. 2 shows radiance calculations for nadir viewing direction at the top of the atmosphere using the parameterizations reptran and lowtran and line-by-line calculations.

The reptran parameterization (Gasteiger et al., 2014) has recently been included in libRadtran. In reptran integrals over spectral intervals, e.g. integrated over a narrow spectral band or an instrument channel response function, are parameterized as weighted means over representative wavelengths similar to the method described by Buehler et al. (2010). The selection of an optimum set of representative wavelengths is based on accurate line-by-line simulations for top-of-atmosphere radiances of a highly variable set of atmospheric states. The ARTS (Atmospheric Radiative Transfer Simulator) model (Eriksson et al., 2011) including state-of-the-art continuum models and spectroscopic data from HITRAN 2004 (Rothman et al., 2005) were used to calculate the gas absorption properties. For wavelengths below $1130 \mathrm{~nm}$ measured absorption cross sections of $\mathrm{O}_{3}$ (Molina and Molina, 1986), $\mathrm{O}_{4}$ (Greenblatt et al., 1990), and $\mathrm{NO}_{2}$ (Burrows et al., 1998) are included, as they are not covered by HITRAN or the continua (see also Sect. 4.2). Three-band resolutions (fine: $1 \mathrm{~cm}^{-1}$; medium: $5 \mathrm{~cm}^{-1}$; and coarse: $15 \mathrm{~cm}^{-1}$ ) are available in the solar and thermal spectral range, as well as a number of instruments on the following satellites: ADEOS (Advanced Earth Observing Satellite), ALOS (Advanced Land Observing Satellite), EarthCARE (Earth Clouds, Aerosols and Radiation Explorer), Envisat (Environmental Satellite), ERS (European RemoteSensing Satellite), Landsat, MSG (Meteosat Second Generation), PARASOL (Polarization and Anisotropy of Reflectances for Atmospheric Sciences coupled with Observations from Lidar), Proba (Project for On-Board Autonomy), Sentinel, Seosat (Satélite Espanol de Observación de la Tierra), and SPOT (Satellite Pour l'Observation de la Terre). The parameterization has been validated by comparison to high spectral resolution calculations. For solar and thermal radiation at the top of atmosphere, as well as for solar radiation on the ground, the mean parameterization error is in the range of $1 \%$. The mean error is slightly larger than $1 \%$ for thermal radiation at the surface.

The LOWTRAN (low-resolution transmission)-band model adopted from the SBDART (Santa Barbara DISORT 
Table 2. Absorption parameterizations in libRadtran.

\begin{tabular}{|c|c|c|c|}
\hline Name & Description & Application & References \\
\hline reptran_channel & $\begin{array}{l}\text { satellite channels parameterized using } \\
\text { representative wavelengths; }\end{array}$ & $\begin{array}{l}\text { fast and accurate simulations } \\
\text { for various satellite instruments }\end{array}$ & Gasteiger et al. (2014) \\
\hline lowtran & $\begin{array}{l}\text { LOWTRAN band model; } \\
\text { solar and thermal region, resolution } 20 \mathrm{~cm}^{-1}\end{array}$ & $\begin{array}{l}\text { pseudo-spectral calculations of } \\
\text { radiances }\end{array}$ & $\begin{array}{l}\text { Ricchiazzi et al. (1998) } \\
\text { Pierluissi and Peng (1985) }\end{array}$ \\
\hline fu & $\begin{array}{l}\text { correlated_k distributions for solar ( } 6 \text { bands) } \\
\text { and thermal ( } 12 \text { bands) regions; } \\
\text { optimized for climate models }\end{array}$ & $\begin{array}{l}\text { calculation of integrated solar } \\
\text { and thermal irradiance, } \\
\text { radiative forcing }\end{array}$ & Fu and Liou $(1992,1993)$ \\
\hline
\end{tabular}

Atmospheric Radiative Transfer) radiative transfer model (Ricchiazzi et al., 1998) is also included in libRadtran.

For the simulation of radiances and irradiance, we recommend to use reptran because it is faster and more accurate than lowtran.

Several correlated-k parameterizations with different numbers of bands, i.e. different accuracy, are included in libRadtran. For the calculation of integrated solar and thermal irradiance and heating rates, the correlated-k parameterizations by Kato et al. (1999) and Fu and Liou (1992, 1993) are recommended. Also for the calculation of heating/cooling rates in the higher atmosphere (above $\sim 20 \mathrm{~km}$ ), we recommend these parameterizations because reptran and lowtran are affected by large errors.

\subsection{Molecular absorption cross sections}

For the spectral region from 160 to $850 \mathrm{~nm}$, libRadtran includes measured absorption cross sections of various molecules in the atmosphere (see Table 3). Using the option mol_abs_param crs, these cross sections are used instead of the default reptran parameterization. For wavelengths below $500 \mathrm{~nm}$, reptran yields approximately the same results as mol_abs_param crs because the cross sections from HITRAN and the continua are very small at these wavelengths and the same measured cross sections are relevant in both cases.

For $\mathrm{O}_{2}$ for instance the cross section data include the Schumann-Runge bands between 176 and $192.6 \mathrm{~nm}$ and the Herzberg continuum between 205 and $240 \mathrm{~nm}$. Ozone ab- sorption bands are for example the Huggins bands between 320 and $360 \mathrm{~nm}$ and the Chappuis bands between 375 and $650 \mathrm{~nm}$. Using the option crs_model the user may specify which cross section data should be used in the simulations. Alternatively with crs_file, the users may specify their own absorption cross section data.

\subsection{Line-by-line calculations}

In the shortwave infrared, thermal infrared, and microwave region, we find a huge number of absorption lines that are due to vibrational or rotational transitions in molecules. A line-by-line model is required in order to calculate spectrally resolved radiances. Line-by-line models take the absorption line positions as well as line strength parameters from spectral databases like HITRAN, calculate line broadening, which depends on pressure and temperature in the atmosphere, and finally obtain absorption optical thickness profiles. libRadtran does not include a line-by-line model but it allows one to specify absorption optical thickness profiles using the option mol_tau_file abs. It is convenient to use the ARTS model (Eriksson et al., 2011) to generate spectrally resolved molecular absorption data because it outputs the format required by libRadtran. ARTS includes a comprehensive line-by-line module, it allows one to use different spectroscopic databases like HITRAN as input and it also includes various state-of-the-art absorption continuum models. The toolbox Py4CATS (Schreier and Böttger, 2003; Schreier, 2006; Schreier and Kohlert, 2008) which can be downloaded from www.libradtran.org, also includes conve- 
Table 3. Absorption cross section data included in libRadtran; the non-default parameterizations are put in parentheses.

\begin{tabular}{lrl}
\hline Molecule & $\begin{array}{r}\text { wavelength } \\
\text { range [nm] }\end{array}$ & reference \\
\hline $\mathrm{BrO}$ & $312-385$ & Wahner et al. (1988) \\
$\mathrm{CO}_{2}$ & $119-200$ & Yoshino et al. (1996) \\
$\mathrm{HCHO}$ & $300-386$ & Cantrell et al. (1990) \\
$\mathrm{NO}_{2}$ & $240-760$ & (Bogumil et al., 2003) \\
& $231-794$ & Burrows et al. (1998) \\
$\mathrm{O}_{2}$ & $108-160$ & Ogawa and Ogawa (1975) \\
& $160-175$ & Yoshino et al. (2005) \\
& $175-204$ & Minschwaner et al. (1992) \\
& $205-240$ & Yoshino et al. (1988) \\
$\mathrm{O}_{3}$ & $116-185$ & Ackerman (1971) \\
& $185-350$ & Molina and Molina (1986) \\
& $195-345$ & (Daumont et al., 1992)/ \\
& & (Malicet et al., 1995) \\
& $245-340$ & (Bass and Paur, 1985) \\
& $240-850$ & (Bogumil et al., 2003) \\
& $400-850$ & WMO (1986) \\
$\mathrm{O}_{4}$ & $330-1130$ & Greenblatt et al. (1990) \\
$\mathrm{OClO}$ & $240-480$ & Wahner et al. (1987) \\
$\mathrm{SO}_{2}$ & $239-395$ & Bogumil et al. (2003) \\
\hline
\end{tabular}

nient command line programs to generate spectrally resolved absorption data. The Py4CATS tools, however, do not include continuum models; hence, it should only be used for simulations where the continua are not relevant.

\subsection{Rayleigh-scattering cross sections}

The Rayleigh-scattering cross sections are by default calculated using Eqs. (22)-(23) of Bodhaine et al. (1999). Using the option crs_model rayleigh, the user may select Eq. (29) of Bodhaine et al. (1999) or the formulas proposed by Nicolet (1984) and Penndorf (1957), respectively. The analytical Rayleigh-scattering phase matrix $\mathbf{P}_{\mathrm{R}}$ (Hansen and Travis, 1974) is

$$
\begin{aligned}
& \mathbf{P}_{\mathrm{R}}(\Theta)=
\end{aligned}
$$

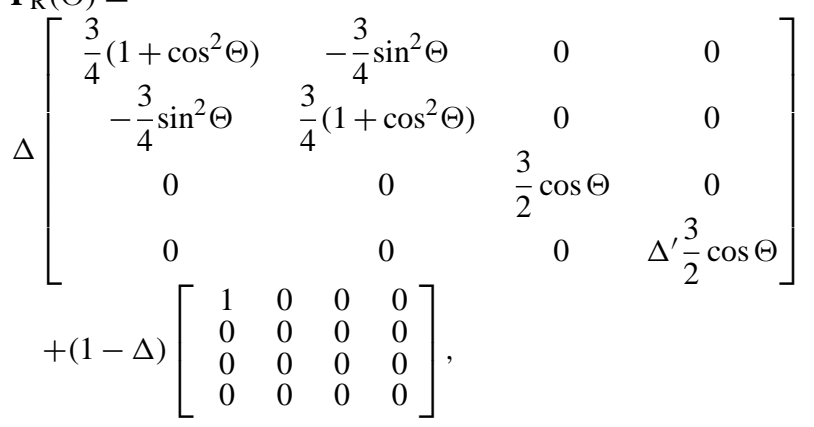

where

$$
\Delta=\frac{1-\delta}{1+\delta / 2}, \quad \Delta^{\prime}=\frac{1-2 \delta}{1-\delta},
$$

and $\delta$ is the depolarization factor that accounts for the anisotropy of the molecules; $\delta$ is also calculated according to Bodhaine et al. (1999). The Rayleigh phase matrix for $\delta=0$ is shown in Fig. 3. For calculations neglecting polarization only the $(1,1)$ element of the phase matrix, which corresponds to the scattering phase function, is required.

\section{Aerosols}

Besides the models by Shettle (1989), which are described in Mayer and Kylling (2005), libRadtran now includes additional aerosol properties based on the OPAC (Optical Properties of Aerosols and Clouds) database (Hess et al., 1998). OPAC provides the required parameters for single-scattering calculations: size distribution parameters, refractive indices, and the density of the material. Data are available for the spectral range from $250 \mathrm{~nm}$ to $40 \mu \mathrm{m}$ for the following basic aerosol types: insoluble (inso), water soluble (waso), soot (soot), sea salt accumulated (ssam), sea salt coarse mode ( $\mathrm{s} \mathrm{cm}$ ), mineral nucleation mode ( $\mathrm{minm})$, mineral accumulated mode (miam), mineral coarse mode $(\mathrm{micm})$, mineral transported (mitr), and soluble sulfate aerosol (suso). For the soluble aerosols the parameters depend on humidity because the aerosol particles swell in humid air. Relative humidities of $0,50,70,80,90,95,98$, and $99 \%$ are included in OPAC. The option aerosol_species_file allows one to define arbitrary mixtures of these basic types or to select pre-defined mixtures from OPAC, such as, e.g., cont inental_average, for which uvspec automatically uses the optical properties closest to the background humidity profile.

Optical properties of all basic aerosol types were calculated using libRadtran's Mie tool (see Sect. 10.1). For mineral aerosols, which are highly aspherical, we additionally provide optical properties calculated with the T-matrix method (Mishchenko and Travis, 1998), assuming an aspect ratio distribution of prolate spheroids as described by Koepke et al. (2015).

As an example Fig. 3 shows the phase matrix elements of the basic OPAC aerosol types, of liquid cloud droplets with an effective radius of $10 \mu \mathrm{m}$ and the Rayleigh-scattering phase matrix. Note that for spherical particles only four elements of the $4 \times 4$ scattering phase matrix are independent whereas for aspherical particles six elements are required (see, e.g., Hansen and Travis, 1974). Figure 4 shows the absorption and the scattering optical thicknesses (integrated from the surface to the top of the atmosphere) for the standard aerosol mixtures in the spectral region from 300 to $800 \mathrm{~nm}$. As expected, the optical thickness of the urban aerosol is the largest and that of the antarctic aerosol the smallest. In general the continental aerosol mixtures show a stronger wavelength dependency than the maritime mixtures.

The users may also provide their own optical properties data, which may be generated using libRadtran's Mie tool or 
Table 4. Water clouds parameterizations in libRadtran.

\begin{tabular}{llll}
\hline Name & Description & Application & References \\
\hline hu & $\begin{array}{l}\text { default setting. Simple parameterization, uses } \\
\text { Henyey-Greenstein phase function to approx- } \\
\text { imate Mie phase function }\end{array}$ & irradiance, heating rates & Hu and Stamnes (1993) \\
\hline echam4 & $\begin{array}{l}\text { very simple two-band parameterization of } \\
\text { ECHAM4 climate model }\end{array}$ & $\begin{array}{l}\text { comparison of irradiance to re- } \\
\text { sults from ECHAM4 }\end{array}$ & Roeckner et al. (1996) \\
\hline mie & $\begin{array}{l}\text { optical properties calculated using Mie theory, } \\
\text { include full phase matrices }\end{array}$ & (polarized) radiances & generated using Mie code by \\
& & & Wiscombe (1980) \\
\hline
\end{tabular}
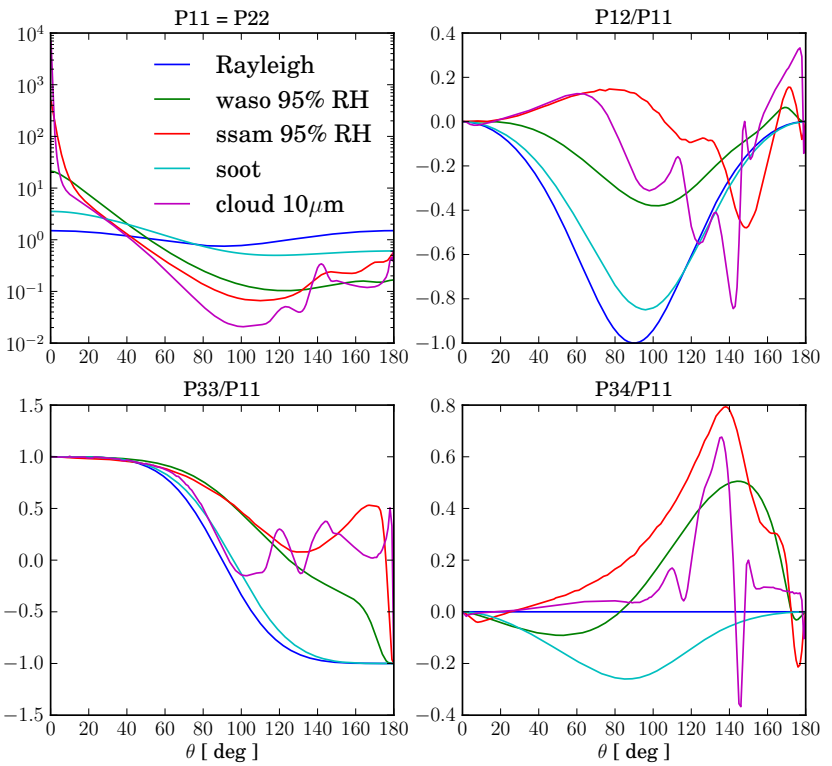

Figure 3. Phase matrix elements for the basic OPAC aerosol types "water soluble" (waso), "sea salt accumulated mode" (s sam), and soot, for a water cloud with a droplet effective radius of $10 \mu \mathrm{m}$, and for Rayleigh scattering (with $\delta=0$ ) at a wavelength of $350 \mathrm{~nm}$. $\theta$ is the scattering angle, i.e. the angle between incoming and scattered directions.

other external programs; more detailed instructions are provided in the libRadtran user guide.

\section{Clouds}

\subsection{Water clouds}

Table 4 summarizes the parameterizations of water cloud optical properties, which may be selected in libRadtran using the option wc_properties.

For the simulation of irradiance and heating rates, it is normally sufficient to use a simple parameterization to convert from cloud liquid-water content and droplet effective radius to the respective optical properties: extinction coefficient, single-scattering albedo, and asymmetry parameter. For this purpose libRadtran includes the parameterization generated by Hu and Stamnes (1993).

For the simulation of radiances more accurate optical properties are needed and the phase function should not be approximated by a Henyey-Greenstein function as it is done in Hu and Stamnes (1993). Therefore, we have pre-calculated cloud optical properties using libRadtran's Mie tool, assuming that the cloud droplets are gamma distributed:

$n(r)=N r^{\alpha} \exp \left(-\frac{r}{r_{\text {eff }} \cdot v_{\text {eff }}}\right) ; \quad \alpha=\frac{1}{v_{\text {eff }}}-3$.

Calculations have been performed for effective radii $r_{\text {eff }}$ from 1 to $25 \mu \mathrm{m}$ with a step width of $1 \mu \mathrm{m}$. The effective variance was set to a value of $v_{\text {eff }}=0.1$ and the constant $N$ was determined by normalization. The size distributions were cut off at a minimum radius of $0.02 \cdot r_{\mathrm{eff}}$ and a maximum radius of $8 \cdot r_{\text {eff }}$. The size distribution bins are sampled on a size parameter $\left(\frac{2 \pi r}{\lambda}\right)$ grid with a resolution of 0.003 . This fine resolution is necessary to obtain smooth phase matrices. The pre-calculated data include the wavelength ranges from 250 to $2200 \mathrm{~nm}$ (solar) with a resolution of $10 \mathrm{~nm}$ and the range from 2.2 to $100 \mu \mathrm{m}$ (thermal) in 100 steps of equal wavenumbers. The refractive index of water has been taken from Warren (1984). In the solar (thermal) region, the phase matrices are computed from 5000 (500) Legendre polynomials. In the optical properties files, 129 of the Legendre polynomials are stored, as well as the phase matrix elements, which are stored on scattering angle grids $\theta$ optimized such that the error of the phase matrix - when interpolated linearly in $\cos \theta$ between the grid points - is smaller than $1 \%$. As an example Fig. 3 shows the four phase matrix elements of a cloud droplet distribution with $r_{\text {eff }}=10 \mu \mathrm{m}$ at $350 \mathrm{~nm}$. Here the cloudbow at $\theta \approx 140^{\circ}$ is clearly visible in the $P_{11}$ and $P_{12} / P_{11}$ elements of the phase matrix. $P_{12} / P_{11}$ corresponds to the degree of polarization in the principal plane after single scattering; it can be seen that the maximum in the cloudbow region is about $80 \%$. The mystic solver uses the phase matrix stored on the $\theta$-grid, whereas all other solvers use the Legendre polynomials, except for the intensity correction in disort, which uses the phase function (see also Buras et al., 2011). 

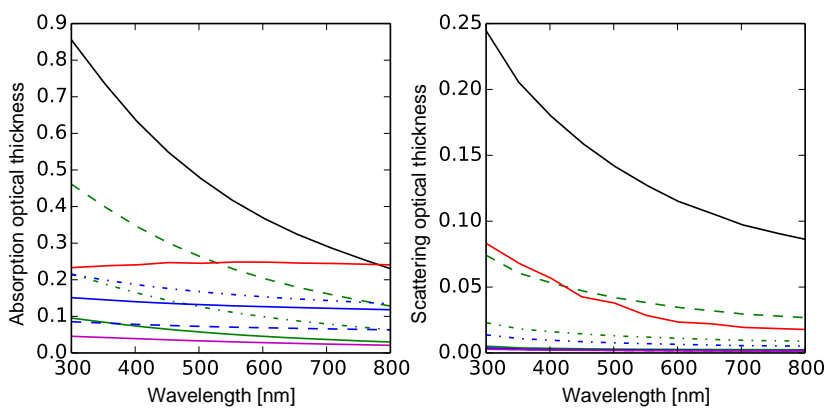

\begin{tabular}{|c|c|c|c|c|}
\hline \multicolumn{5}{|c|}{ Aerosol mixture name } \\
\hline - & Continental_clean & - Maritime_clean & - & Urban \\
\hline$\cdots$ & Continental_average & -.. Maritime_polluted & - & Desert \\
\hline-- & Continental_polluted & - - Maritime_tropical & - & Antarctic \\
\hline
\end{tabular}

Figure 4. Absorption (left) and scattering (right) optical thickness for various aerosol mixtures specified using the option aerosol_species_file. The aerosol optical properties as well as the mixtures have been generated based on OPAC (Hess et al., 1998) parameters.

For specific applications, e.g. different size distributions, the user can easily generate optical properties using libRadtran's Mie tool.

\subsection{Ice clouds}

For ice clouds libRadtran includes a variety of parameterizations (see Table 5) from which the user may select the most appropriate one for a specific application by specifying the option ic_properties. Ice clouds are more complex than water clouds because they consist of ice crystals of different shapes. Some of the ice cloud parameterizations allow the crystal habit (ic_habit) to be specified.

As described in the previous section the exact phase matrix is not needed when irradiance are calculated. For this purpose the parameterizations by $\mathrm{Fu}$ (1996), Fu et al. (1998), and Key et al. (2002) are included in libRadtran. Fu (1996) and Fu et al. (1998) approximate the phase function by a HenyeyGreenstein function. Key et al. (2002) is slightly more accurate because it uses a double-Henyey-Greenstein function, which represents the backscattering of ice crystals much better. The parameterization is based on single-scattering calculations for various ice crystal habits and on measured size distributions. It is available in the wavelength range from 0.2 to $5 \mu \mathrm{m}$. Based on single-scattering data provided by P. Yang and on the size distributions from J. R. Key we have extended the original parameterization by Key et al. (2002) to the thermal wavelength region up to $100 \mu \mathrm{m}$.

For accurate radiance calculations the parameterizations by Baum et al. (2005a, b) (baum) and the newer one by Heymsfield et al. (2013), Yang et al. (2013), and Baum et al. (2014) (baum_v36) are available: baum includes full phase functions for a mixture of particle shapes, the parameterization is based on single-scattering properties of smooth ice crystals and on a large number of measured size distributions. baum_v36 includes full phase matrices and three different habit models: a general habit mixture similar to baum but for rough ice crystals, and the single habits solid column and aggregate, both of them severely roughened.

We have generated two further parameterizations (hey and yang2013) for individual habits, which also include the full phase matrices (see Appendix A): hey is available for the wavelength region from 0.2 to $5 \mu \mathrm{m}$ for smooth particles in the effective radius range from 5 to $90 \mu \mathrm{m}$. The full wavelength region from $200 \mathrm{~nm}$ to $99 \mu \mathrm{m}$ is available for yang2013, effective radii may be in the range from 5 to $90 \mu \mathrm{m}$ and a roughness parameter may also be specified, ranging from smooth to severely rough. For the yang2013 parameterization, the single-scattering properties of nine individual ice crystal habits, which are commonly observed in ice clouds, have been taken from the database by Yang et al. (2013). The hey parameterization was generated before this database existed and it is based on single-scattering data provided by Hong Gang, who used the improved geometrical optics method (IGOM), the same method as used by Yang et al. (2013).

Please refer to the libRadtran user guide for a list of available habits for each parameterization.

Figure 5 shows the phase matrix elements of ice crystal distributions with an effective radius of $40 \mu \mathrm{m}$ at $550 \mathrm{~nm}$ wavelength. The red lines correspond to smooth crystals and the blue lines to severely rough crystals. The individual habits are for the yang2013 parameterization. General habit mixtures, which are available for the hey parameterization based on smooth crystals and for the baum_v36 parameterization based on severely rough crystals, are also shown. For most smooth crystals and also for the general habit mixture ghm of the hey parameterization-scattering features of hexagonal ice crystals, the most prominent being the halo at $22^{\circ}$ scattering angle, are visible in all phase matrix elements. The phase matrices for severely rough crystals do not show halo features and they are relatively similar for all habits. In reality ice clouds are highly variable: There are situations when the halo is visible, in this case obviously there must be regular smooth ice crystals in the cirrus clouds. When no halo is visible, the assumption of severely roughened crystals might be more realistic.

\section{Surface}

\subsection{Bi-directional reflectance distribution functions}

All solvers included in libRadtran may include Lambertian surfaces, while DISORT and MYSTIC can also handle bidirectional reflectance distribution functions. libRadtran provides a variety of BRDFs (bi-directional reflection distribution function), which are listed in Table 6.

Two parameterizations for land surfaces are available. The first is the "RPV (Rahman, Pinty, and Verstraete)" parameter- 
Table 5. Ice cloud parameterizations in libRadtran

\begin{tabular}{|c|c|c|c|}
\hline Name & Description & Application & References \\
\hline fu & $\begin{array}{l}\text { default setting. Simple parameterization using } \\
\text { Henyey-Greenstein phase function. }\end{array}$ & irradiance, heating rates & Fu (1996); Fu et al. (1998) \\
\hline echam4 & $\begin{array}{l}\text { very simple 2-band parameterization of } \\
\text { ECHAM } 4 \text { climate model. }\end{array}$ & $\begin{array}{l}\text { comparison of irradiance to re- } \\
\text { sults from ECHAM4 }\end{array}$ & Roeckner et al. (1996) \\
\hline key & $\begin{array}{l}\text { parameterization using a double-Henyey- } \\
\text { Greenstein phase function, covers wavelength } \\
\text { range from } 0.2 \text { to } 5.0 \mu \mathrm{m} \text {. Available for various } \\
\text { habits. }\end{array}$ & irradiance, heating rates & Key et al. (2002) \\
\hline yang & $\begin{array}{l}\text { Similar to key but based on different single- } \\
\text { scattering calculations and extended to wave- } \\
\text { lengths up to } 100 \mu \mathrm{m} \text {. Below } 3.4 \mu \mathrm{m} \text { equivalent } \\
\text { to key. }\end{array}$ & irradiance, heating rates & $\begin{array}{l}\text { Key et al. (2002), Yang et al. } \\
(2005)\end{array}$ \\
\hline baum & $\begin{array}{l}\text { bulk optical properties including phase func- } \\
\text { tions for a realistic mixture of habits. Covers } \\
\text { wavelength range from } 0.4 \text { to } 2.2 \mu \mathrm{m} \text { and from } \\
3.1 \text { to } 100 \mu \mathrm{m} \text {. }\end{array}$ & radiances & Baum et al. $(2005 a, b)$ \\
\hline baum_v36 & $\begin{array}{l}\text { bulk optical properties including phase matrices } \\
\text { for three microphysical models: general habit } \\
\text { mixture, solid columns or rough aggregates. All } \\
\text { models include severely rough particles. Covers } \\
\text { wavelength range from } 0.2 \text { to } 99 \mu \mathrm{m} \text {. }\end{array}$ & (polarized) radiances & $\begin{array}{l}\text { Heymsfield et al. (2013); Yang } \\
\text { et al. (2013); Baum et al. (2014) }\end{array}$ \\
\hline hey & $\begin{array}{l}\text { bulk optical properties including phase matri- } \\
\text { ces based on single-scattering calculations for } \\
\text { smooth crystals, covers wavelength range from } \\
0.2 \text { to } 5 \mu \mathrm{m} \text {, includes } 6 \text { habits and a habit mix- } \\
\text { ture. }\end{array}$ & (polarized) radiances & $\begin{array}{l}\text { Single-scattering properties } \\
\text { generated by Hong Gang using } \\
\text { the code by Yang et al. (2013), } \\
\text { Appendix A }\end{array}$ \\
\hline yang2013 & $\begin{array}{l}\text { bulk optical properties including phase matrices } \\
\text { for } 9 \text { habits and } 3 \text { degrees of roughness, covers } \\
\text { wavelength range from } 0.2 \text { to } 99 \mu \mathrm{m} \text {. }\end{array}$ & (polarized) radiances & Yang et al. (2013), Appendix A \\
\hline
\end{tabular}

ization by Rahman et al. (1993) with the extension by Degünther and Meerkötter (2000) for modelling snow-covered surfaces. The second is the "RossLi" BRDF first presented by Roujean et al. (1992). The original RossLi BRDF is used in the AMBRALS (the Algorithm for Model Bi-directional Reflectance Anisotropy of the Land Surface) BRDF modelling framework (Wanner et al., 1997), and consists of four different kernel combinations, of which the RossThickLiSparseReciprocal combination was identified in several studies to be the model best suited for the operational MODIS BRDF/Albedo algorithm (see Schaaf et al., 2002). An additional factor for simulating the hot spot in vegetation canopies was added by Maignan et al. (2004). The version implemented in libRadtran is the RossThickLiSparseReciprocal model as used in MODIS data, as presented in Lucht et al. (2000). The hot spot correction factor can be turned on if required.

As already stated in Mayer and Kylling (2005), but repeated here for completeness, a parameterization of the
BRDF of water surfaces is also included, which depends mainly on wind speed and to a lesser degree on plankton concentration and salinity. For the MYSTIC solver, also the wind direction can be set. In contrast to vegetation where the typical hot spot occurs in the $180^{\circ}$ backscatter direction, the main feature for water is specular reflection. The parameterization in uvspec was adopted from the $6 \mathrm{~S}$ code (Vermote et al., 1997) and is based on the measurements of Cox and Munk (1954a, b) and the calculations of Nakajima and Tanaka (1983). A vector version of the ocean parameterization, developed by Tsang et al. (1985) and Mishchenko and Travis (1997), is available for polarization calculations with MYSTIC. The vector version uses only wind speed as a parameter and does not take into account plankton concentration, salinity or wind direction.

Finally, the parameterization of the surfaces of extraterrestrial solid bodies such as the Moon, asteroids, or the inner planets by Hapke (1993) is available. 
Table 6. The surface reflection models currently implemented in libRadtran.

\begin{tabular}{llrll}
\hline Option name & BRDF type & No. of parameters & References & Solvers \\
\hline albedo & Lambertian & 1 & & \\
brdf_cam & ocean BRDF & $3+1$ & Cox and Munk (1954a, b); Nakajima and Tanaka (1983) & D, M \\
bpdf_tsang & polarized ocean BRDF & 1 & Tsang et al. (1985); Mishchenko and Travis (1997) & M \\
brdf_hapke & planetary \& lunar surfaces & 3 & Hapke (1993) & D, M \\
brdf_ambrals & Ross-Li, MODIS Land Surface, & 3 & Roujean et al. (1992); Wanner et al. (1997); Lucht et al. & D, M \\
& RTLSR & & (2000); Schaaf et al. (2002); Maignan et al. (2004) & \\
brdf_rpv & land surfaces & $3+3$ & Rahman et al. (1993); Degünther and Meerkötter (2000) & D, M \\
\hline
\end{tabular}

D: DISORT; M: MYSTIC; RTLSR: RossThickLiSparse-Reciprocal model, optionally with hot spot parameterization.

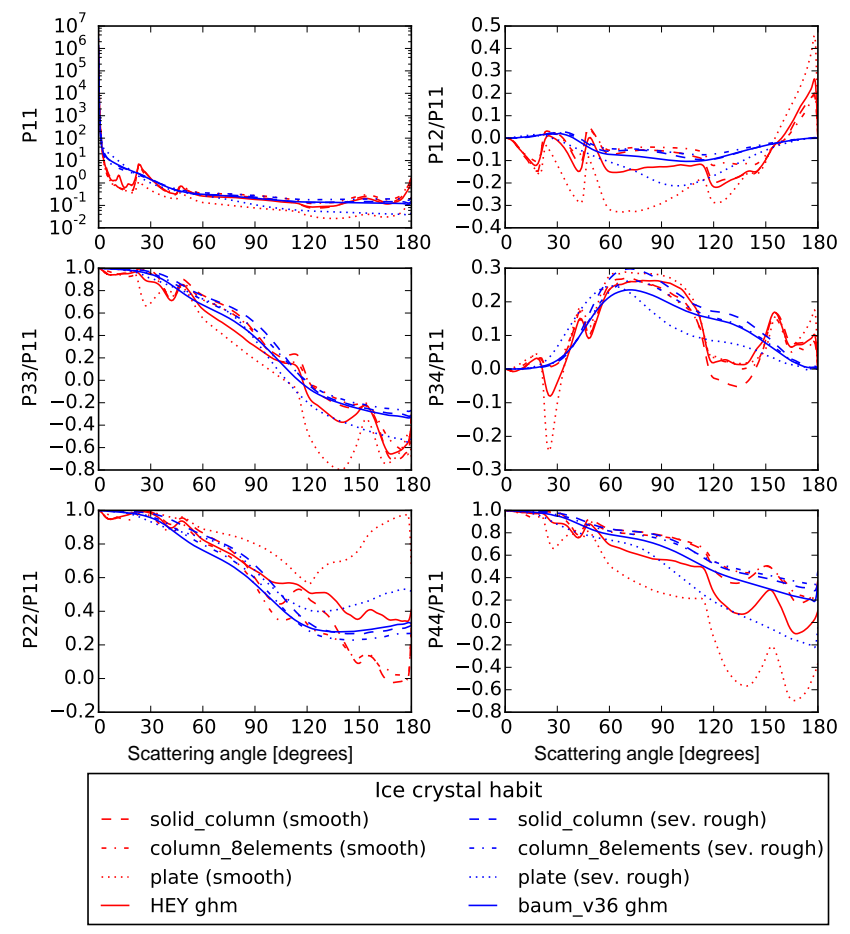

Figure 5. Phase matrix elements of ice crystal distributions with an effective radius of $40 \mu \mathrm{m}$ at $550 \mathrm{~nm}$ wavelength. The red lines correspond to smooth and the blue lines to severely rough crystals. The individual habits (solid-column, column-8elements and plate) are for the parameterization yang2013, and the general habit mixtures $(\mathrm{ghm})$ are for hey including smooth crystals and baum_v36 including severely rough particles.

Only the ocean BRDF parameterizations depend directly on the wavelength. For all other BRDF models, the parameterization can either be given as being constant with wavelength (by using, e.g., the option brdf_rpv), or as a file containing the parameters for each wavelength (using, e.g., brdf_rpv_file).

\subsection{Fluorescence}

For vegetation covered surfaces, a weak solar-induced chlorophyll fluorescence signal is emitted in the red and far- red spectral regions. The contribution of fluorescence to the radiance leaving the bottom boundary is

$L_{g}^{F}(\mu, \phi, \lambda)=F(\lambda)$,

where $F(\lambda)$ is the fluorescence source in the same units as the incoming solar flux at the top of the atmosphere (for example $\left.\mathrm{mW}\left(\mathrm{m}^{2} \mathrm{~nm} \mathrm{sr}\right)^{-1}\right)$. The fluorescence source of radiation is included in the disort solver. It may either be constant or vary as a function of wavelength. Additional surface bidirectional reflection of radiation may also be included. The fluorescence source depends on the solar radiation impinging the vegetation and the type of vegetation. Output from vegetation fluorescence canopy models, such as that described by Miller et al. (2005), may readily be used by uvspec.

\section{Implementation improvements}

\subsection{Multiple atmospheric constituents}

The previous versions of libRadtran were restricted to using at most four types of atmospheric constituents: molecules, aerosols, and water and ice clouds. Any user defined constituent could only be included by replacing, e.g., water clouds with them. Also, it was not possible to use several types of ice cloud habits at the same time.

A recent major internal restructuring of the libRadtran code has now made it possible to use any number of atmospheric constituents for a radiative transfer simulation. The number is only limited by computational memory and time. The new input options needed for loading the additional constituents are profile_file and profile_properties. They work very similar to the cloud input options; merely the name of the constituent needs to be defined.

This option increases the flexibility of libRadtran in many ways; e.g., it can be used to load the optical properties for each size bin of an aerosol or water or ice cloud. This way, the size distribution may differ between the atmospheric layers. An example can be found in Kylling et al. (2013). 


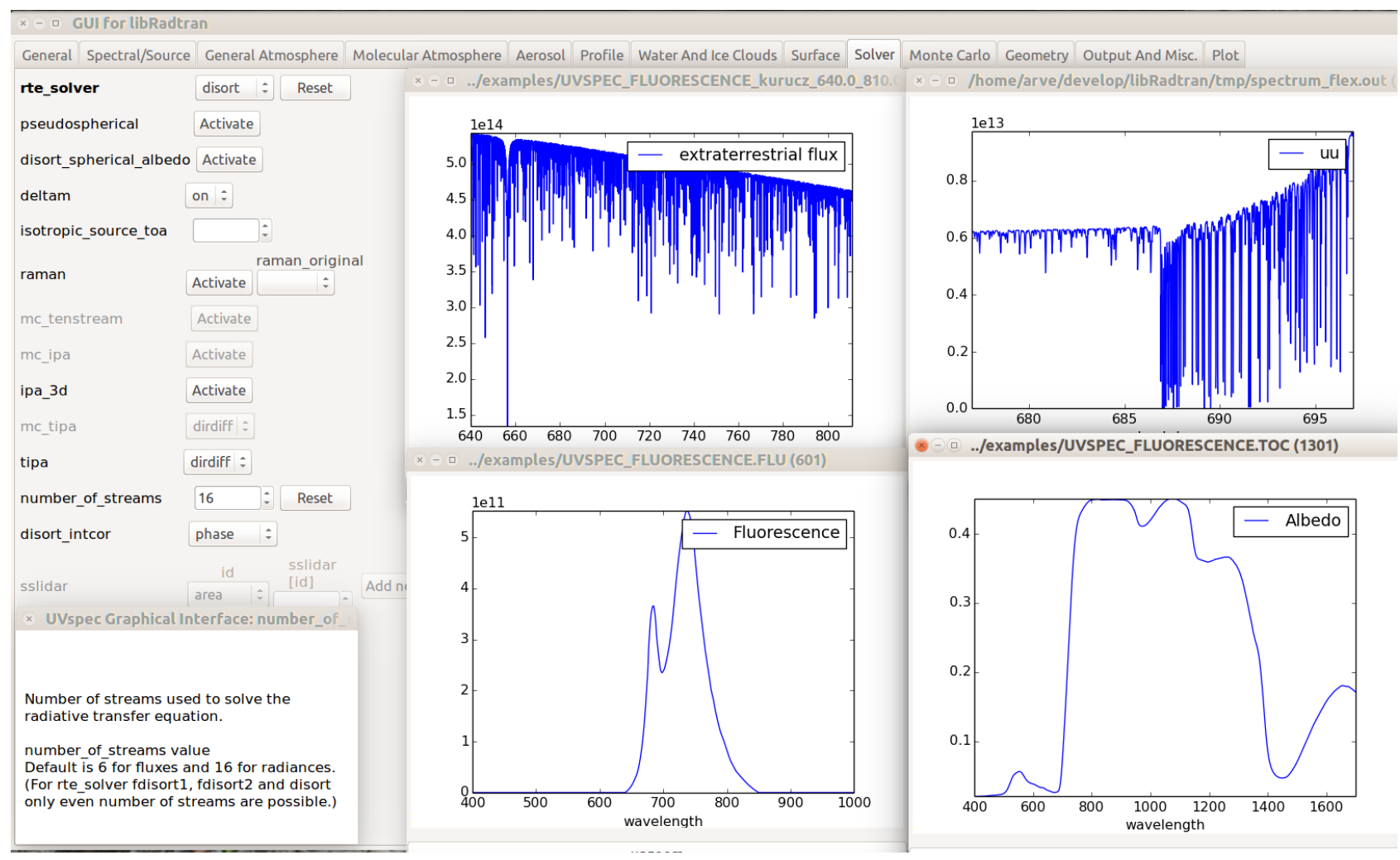

Figure 6. Screenshot of the graphical user interface for a spectral high-resolution simulation of the $\mathrm{O}_{2}$-B band including a fluorescence source. Plots of input and output data are included together with the help information for one option. See text for further explanation.

\subsection{Change of nomenclature and backward compatibility}

As the number of input options had grown to more than 300 over the years, we decided to restructure the language of the input options. The input options now have a largely consistent naming and their usage follows certain rules, making it more easy to find related input options.

We have included a python script in order to provide backward compatibility for long-established libRadtran users. The script can be found in the directory src_py. By invoking the command

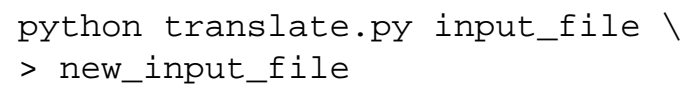

input files written in the old nomenclature will be translated to the new nomenclature automatically. Alternatively, the old input file can be sent directly to uvspec with the following command:

python translate.py input_file | uvspec

\section{Graphical user interface}

The large number of input options available in the uvspec model may appear overwhelming. To help the user to cre- ate uvspec input files a graphical user interface (GUI) has been developed. The GUI organizes the input options in logical groups such as "molecular atmosphere", "aerosol", "surface", etc.; see also the grey bar at the top in Fig. 6. Input options that are set by the user and that will be written to the given input files are shown in bold face (for example option rte_solver in Fig. 6). Options that may be set are shown as normal characters, while options that are not compatible with other set options are greyed (for example in Fig. $6 \mathrm{mc}$-ipa is greyed since it is not possible to combine it with rte_solver set to disort).

Online documentation of the options are available and this is identical to the documentation in the libRadtran user manual. In Fig. 6 the documentation for the option number_of_streams is shown in the lower left corner. The online help is activated by pointing the mouse at the requested input variable.

Input options that refer to input data files, such as wavelength-dependent surface albedo, may be plotted from the GUI. In the example in Fig. 6, the extraterrestrial flux (upper left subplot), the surface fluorescence spectrum (lower left subplot), and surface albedo (lower right subplot) inputs are plotted. Note that the wavelength coverage ( $x$ axis) differs reflecting the different wavelength regions included in the input data files. 

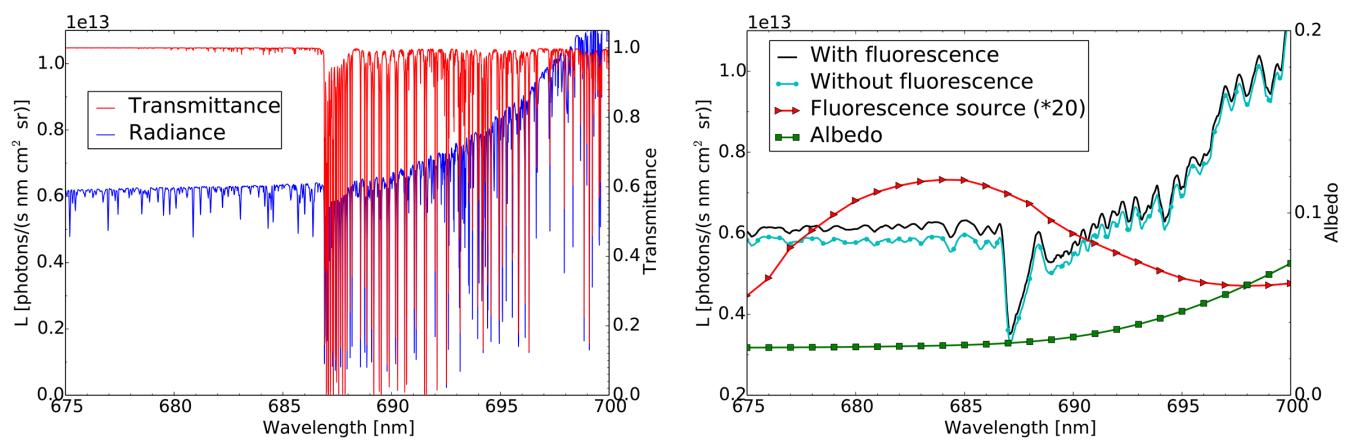

Figure 7. (Left) the transmittance from ARTS output and radiance from uvspec. (Right) the top of the atmosphere nadir viewing radiance in the $\mathrm{O}_{2}-\mathrm{B}$ band with (black line) and without (cyan line with circles) a surface fluorescence source (red line with triangles). The radiances have been convolved with a spectral response function with FWHM of $0.3 \mathrm{~nm}$.

Once all wanted input options are set, they are saved to a user specified file, and uvspec is run from within the GUI. The output from the run may readily be plotted using the GUI. For example, in Fig. 6, the calculated nadir radiance at the top of the atmosphere is shown in the upper right subplot. The GUI includes numerous working examples. Users may add more examples to the GUI specific to their interests.

\section{Other tools}

Several additional tools are included in the libRadtran package. An overview is given in Mayer and Kylling (2005, Table 4). New tools are ssradar, a single-scattering radar simulator (see below), and pmom, which calculates Legendre polynomials for a given phase function.

\subsection{Mie calculations}

The tool for Mie calculations (mie) has been extended considerably. The user may select between two Mie codes, MIEVO by Wiscombe (1980) or bhmie by Bohren and Huffman (1983). The tool allows one to generate input optical properties for uvspec calculations for arbitrary size distributions. It generates full phase matrices, which are stored on optimized angular grids for a user-defined accuracy. The radiative transfer solvers MYSTIC and DISORT with the new intensity correction method (Buras et al., 2011) use the phase functions/matrices rather than Legendre polynomials, which are calculated by the Mie codes.

\subsection{Single-scattering radar simulator}

Single-scattering radar (ssradar) is a stand-alone 1-D pure Rayleigh-scattering cloud radar simulator that handles arbitrary cloud layers and droplet size distributions as well as tilted viewing angles and supercooled water droplets. The radar reflectivity factor is calculated directly from the droplet distribution with $Z=\sum_{i} n_{i} D_{i}^{6}$ (Rinehart, 2010) where $D$ is the droplet diameter and $n_{i}$ the distribution number density for the discrete interval $D_{i}, D_{i+1}$. Internally available distributions are gamma and log-normal, arbitrary distributions can be entered using input files.

\section{Some applications}

The libRadtran package has been used for numerous applications. Many of these are listed under the publications link at http://www.libradtran.org. The examples directory also includes a number input files that may be used especially by new users to create input files. Below some applications of libRadtran are described.

\section{1 uvspec and ARTS}

The high number of absorption lines in the shortwave infrared and the thermal infrared requires a line-by-line approach to resolve the spectral structure. Below it is shown how molecular absorption data from ARTS may be combined with uvspec to perform line-by-line calculations in both the solar and thermal parts of the spectrum. For both examples the spectral resolution, the molecules to be included and the line function properties are specified in the input to ARTS. It is noted that the same ambient atmospheric profile should be used in both, ARTS and uvspec.

\subsubsection{Solar source}

Solar induced chlorophyll fluorescence is emitted in the 660 to $800 \mathrm{~nm}$ spectral region with two broad peaks at about 685 and $740 \mathrm{~nm}$. In this spectral region are the $\mathrm{O}_{2}-\mathrm{A}$ and $\mathrm{O}_{2}-\mathrm{B}$ bands which contain a large number of absorption lines. Although the fluorescence signal is weak, especially the $\mathrm{O}_{2}-\mathrm{B}$ region holds promise for retrieval of vegetation fluorescence from spectrally high-resolution space-borne instruments (Guanter et al., 2010). In this spectral region the surface albedo is typically low while there is a fluorescence peak around $685 \mathrm{~nm}$ (see red line right plot Fig. 7). The optical depths from ARTS are input to uvspec, which calcu- 
lates the top of the atmosphere radiance (blue line, left plot of Fig. 7) including the fluorescence signal (red line, right plot of Fig. 7), surface albedo (green line, right plot of Fig. 7), and molecular scattering. Measurements may be made at a lower spectral resolution. The right plot of Fig. 7 shows radiance spectra convolved with a triangular spectral response function with a full width at half maximum (FWHM) of $0.3 \mathrm{~nm}$ using the conv tool of libRadtran. The spectral response function was generated with the make_slitfunction tool. Spectra with (blue line) and without (purple line) fluorescence are presented. It is seen that the fluorescence signal is relatively larger when the surface albedo is low, below about $690 \mathrm{~nm}$, compared to larger wavelengths.

\subsubsection{Thermal source}

The Infrared Atmospheric Sounding Interferometer (IASI) on board the MetOp satellite measures the radiance from 645 to $2760 \mathrm{~cm}^{-1}(15.50-3.6 \mu \mathrm{m})$ with a spectral resolution of $0.25 \mathrm{~cm}^{-1}$. Its main purpose is high-resolution atmospheric sounding of temperature and humidity, and trace gas column retrievals (Clerbaux et al., 2009; Hilton et al., 2011). It may also be used to detect volcanic ash (see Clarisse et al., 2013, and references therein).

The top panel of Fig. 8 shows IASI spectra from a granule covering the ash cloud following the eruption of Mt Kelud, Indonesia, in February 2014. The spectra are classified as cloudless (green), ice cloud (blue), and volcanic ash (red). To investigate the realism of this identification the spectra were simulated with ARTS/uvspec. For all simulated spectra, the surface emissivity was set equal to one which is representative for water. The simulated spectra are shown in the bottom plot of Fig. 8.

The cloudless spectrum has brightness temperatures representative for the ocean at these latitudes. The main molecular absorption features in this part of the spectrum are water vapour lines throughout the spectrum, ozone (broad band feature centred around $1050 \mathrm{~cm}^{-1}$ ), and $\mathrm{CO}_{2}$ (feature below $800 \mathrm{~cm}^{-1}$ ). The data from ARTS include absorption lines from these molecules. In the cloudless spectrum the ozone band around $1050 \mathrm{~cm}^{-1}$ has a lower brightness temperature than the radiation at lower and higher wavenumber, indicating that the radiation in the ozone band was emitted at a higher altitude with lower temperature than the surface. Overall the ARTS/uvspec cloudless spectrum agrees well with the measured spectrum.

For the simulation with an ice cloud, the ice cloud was located between 12 and $13 \mathrm{~km}$. Ice water content was set to $1 \mathrm{~g} \mathrm{~m}^{-3}$. The ice particles were assumed to consist of solid columns with $r_{\text {eff }}=40.0 \mu \mathrm{m}$. The ice cloud parameterization ic_properties yang was selected. The spectrum identified as ice cloud (blue curve in top plot of Fig. 8) appears saturated for nearly all wavenumbers except for the ozone band centred around $1050 \mathrm{~cm}^{-1}$. The rather low brightness temperature and wavenumber-independent behaviour outside
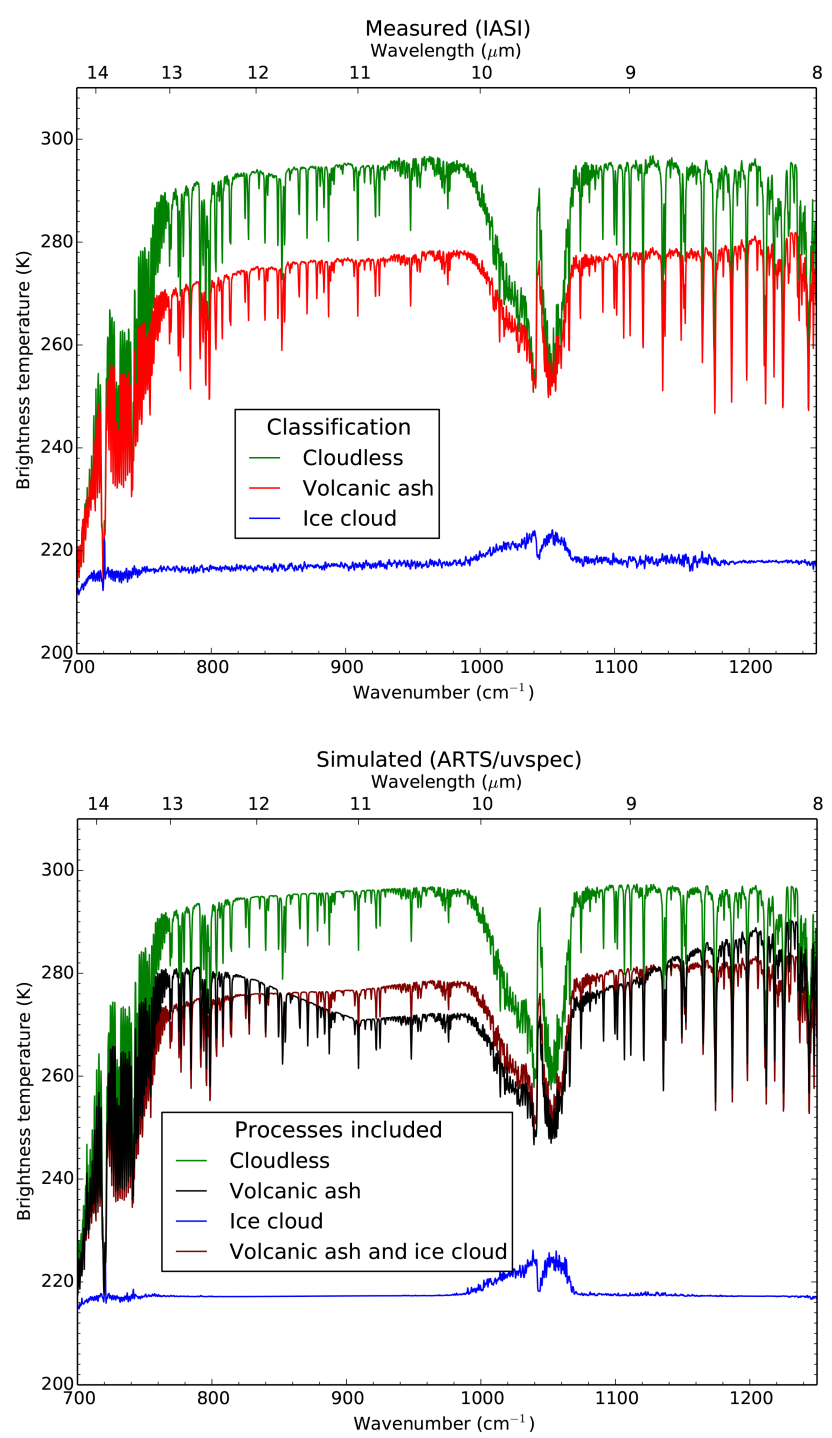

Figure 8. (Top plot) brightness temperature spectra for different locations as measured by IASI on 15 February 2014, 02:33 UTC, during the Mt Kelud, Indonesia, eruption. Tentative classification of the spectra is given in the legend. See text for details. (Bottom plot) simulated brightness temperature spectra using ARTS/uvspec. The atmospheric processes included in the simulations are given in the legend.

the ozone band, indicates that this is an ice cloud and that it is opaque. The simulation with an ice cloud (blue curve in bottom plot of Fig. 8) agrees well with the measured spectrum. The higher temperatures in the ozone band implies that this radiation was emitted at a higher altitude in the stratosphere where the temperature is higher than at the altitude of the cloud.

The ash simulation included an ash cloud between 17 and $18 \mathrm{~km}$. The ash particles were assumed to be made of andesite, spherical and mono-disperse with a radius of $3 \mu \mathrm{m}$. The refractive index of andesite was taken from Pollack et al. 
(1973) and the optical properties were calculated using the mie tool. The ash density was $1 \times 10^{-3} \mathrm{~g} \mathrm{~m}^{-3}$ which corresponds to a mass loading of $1 \mathrm{~g} \mathrm{~m}^{-2}$ for a $1 \mathrm{~km}$ thick cloud.

The red curve in the top plot of Fig. 8 is classified as ash using the difference in brightness temperature method described by Clarisse et al. (2010). This spectrum has a lower brightness temperature than the cloudless spectrum indicating a colder effective emitting temperature overall. The general spectral shape is similar to the cloudless spectrum below $1000 \mathrm{~cm}^{-1}$. Above about $1200 \mathrm{~cm}^{-1}$ the brightness temperature of the cloudless spectrum generally decreases with increasing wavenumber, while the converse is true for the ash spectrum. The simulated ash cloud spectrum (black curve in bottom plot of Fig. 8) differs from the measured spectrum classified as ash. Both the simulated and measured ash spectra increase in magnitude with increasing wavelength above $1100 \mathrm{~cm}^{-1}$, but the simulated spectrum increases more. Below about $900 \mathrm{~cm}^{-1}$ the spectral behaviour of the measured and simulated spectra differs. This may be due to either wrong assumptions about the ash type and hence refractive index and/or the mixing of ice with ash. Ice clouds have an opposite effect of ash clouds on the brightness temperature between 800 and $1000 \mathrm{~cm}^{-1}$, whereas above $1075 \mathrm{~cm}^{-1}$ ice clouds have only a very weak dependence on wavenumber (see Fig. 2 of Gangale et al., 2010). To test if the presence of both ash and ice could reproduce the measured spectrum, simulations were made with both an ash cloud and an ice cloud. The altitude and thickness of the clouds were as above, but the ash cloud density was $2 \times 10^{-4} \mathrm{~g} \mathrm{~m}^{-3}$ and the ice water content $1.5 \times 10^{-2} \mathrm{~g} \mathrm{~m}^{-3}$. The resulting spectrum is shown in maroon in the bottom plot of Fig. 8. The mixed scene with both ash and ice is seen to well reproduce the measured ash spectrum in the top plot of Fig. 8.

\subsection{Simulated satellite image}

Figure 9 shows a simulated satellite image (top) and the corresponding observation (bottom). Three visible channels of the SEVIRI (Spinning Enhanced Visible and Infrared Imager) instrument on the MSG satellite were simulated based on input data from the operational COSMO-DE forecast (Baldauf et al., 2011) of Deutscher Wetterdienst for the 15 July 2012, 12:00 UTC. The spatial resolution of the simulation is $2.8 \mathrm{~km} \times 2.8 \mathrm{~km}$; the SEVIRI observation is $3 \mathrm{~km} \times 3 \mathrm{~km}$ at the sub-satellite point. A false colour composite was generated using the simulated radiance of the $1.6 \mu \mathrm{m}$ channel for red, the $0.8 \mu \mathrm{m}$ radiance for green, and $0.6 \mu \mathrm{m}$ radiance for blue. The simulations were performed using the 1-D disort solver. The MODIS surface albedo data set was used (Schaaf et al., 2002) to set the Lambertian surface albedo. The effective radii of liquid clouds were parameterized according to Martin et al. (1994), and for the optical properties the mie parameterization was applied. Ice cloud effective radii were parameterized according to Wyser (1998) and for the corresponding optical proper-
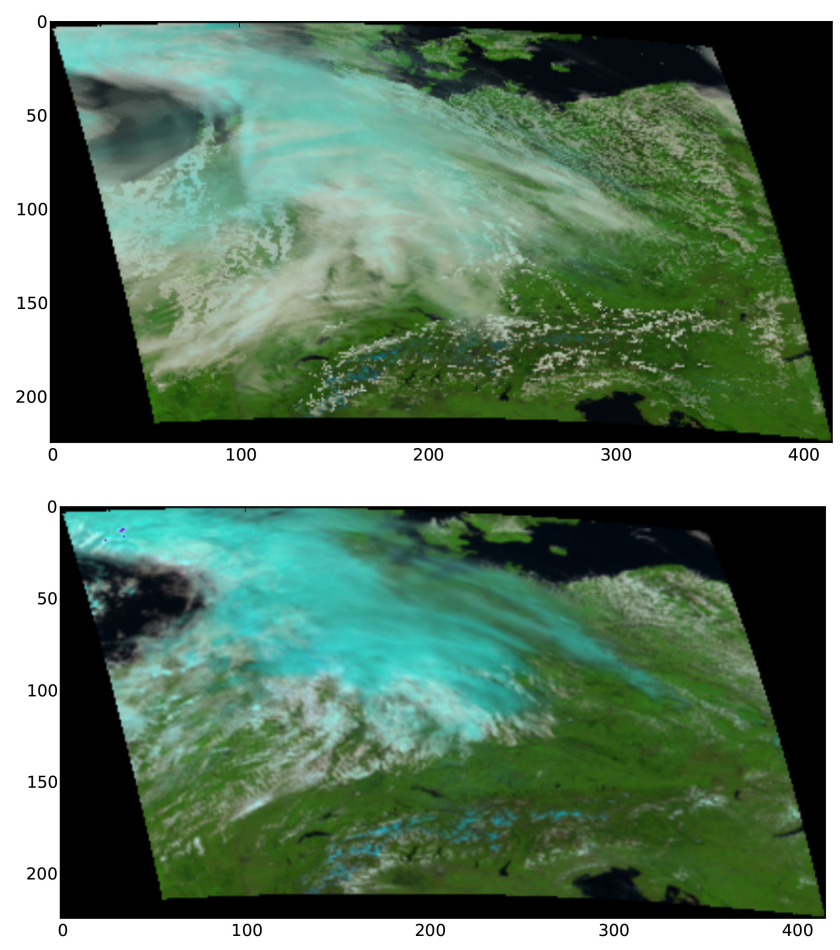

Figure 9. (Top) simulation of MSG-SEVIRI image. False colour composite, where red corresponds to the $1.6 \mu \mathrm{m}$ channel, green to $0.8 \mu \mathrm{m}$, and blue to $0.6 \mu \mathrm{m}$. The simulation was performed using the disort solver with input data from the operational COSMO-DE forecast for the 15 July 2012, 12:00 UTC. The axes correspond to SEVIRI pixel. (Bottom) corresponding SEVIRI image.

ties the parameterization baum_v36 was used with the general habit mixture. Molecular absorption was included using the reptran parameterization. In the false colour composite water clouds appear white and ice clouds appear blueish, because ice absorbs in the region of about $1.6 \mu \mathrm{m}$. The simulated image looks very similar to the observation. A major difference is that the ice clouds in the observation appear more blueish, the reason is that their real optical thickness is larger than in the COSMO-DE forecast.

\subsection{Polarization}

The MYSTIC solver can be applied to simulate multiangle multi-spectral polarized radiances using the option mc_polarisation (Emde et al., 2010). Polarized radiative transfer using MYSTIC has been validated in extensive model intercomparison projects (Kokhanovsky et al., 2010a; Emde et al., 2015).

Figure 10 shows an example for simulations at wavelengths of 443,670 , and $865 \mathrm{~nm}$; these are measured by the POLDER (Polarization and Directionality of the Earth's Reflectances) instrument onboard PARASOL (Deschamps et al., 1994). All simulations are for a solar zenith angle of $30^{\circ}$ and show the reflected radiances (normalized to incom- 

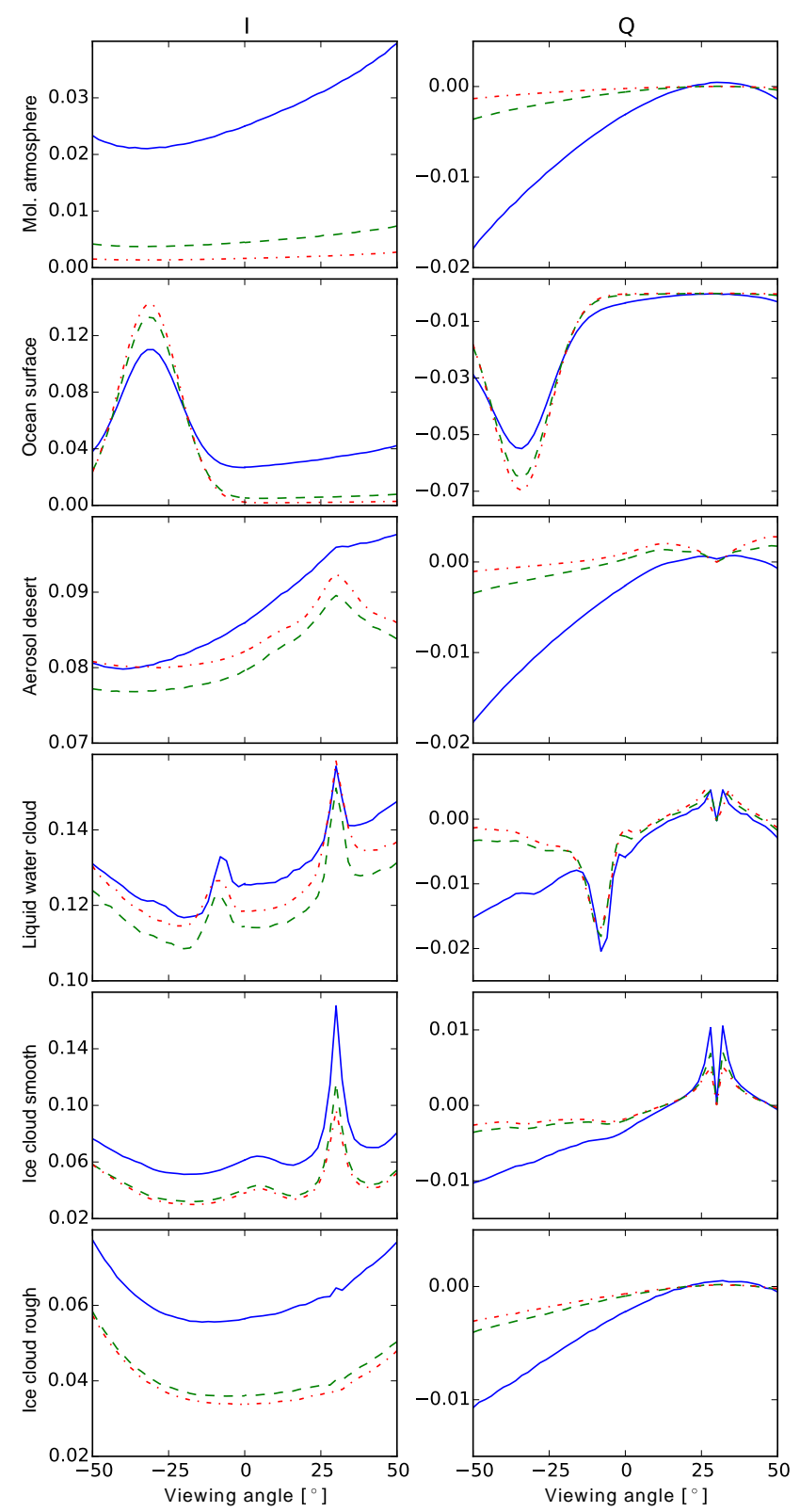

Figure 10. Stokes vector components $I$ and $Q$ at wavelengths of $443 \mathrm{~nm}$ (blue solid lines), $670 \mathrm{~nm}$ (green dashed lines), and $865 \mathrm{~nm}$ (red dashed-dotted lines) for various atmospheric setups (see text for details). The radiances are calculated at the top of the atmosphere for viewing angles from -50 to $50^{\circ}$, where $0^{\circ}$ corresponds to the nadir direction.

ing solar irradiance) at the top of the atmosphere in the solar principal plane. The viewing angle of $30^{\circ}$ corresponds to the exact backscattering direction. The angular resolution is $2^{\circ}$. All simulations are for the US-standard atmosphere. The figure shows the first and second components of the Stokes vector $I$ and $Q$; the components $U$ and $V$ are exactly 0 in the principal plane for symmetry reasons.
The first row shows the results for a clear atmosphere, i.e. Rayleigh scattering and molecular absorption. Here $I$ is largest for the shortest wavelength because the Rayleighscattering cross section decreases with $\lambda^{-4}$, where $\lambda$ is the wavelength. The absolute value of $Q$ also increases with increasing Rayleigh-scattering cross section. A negative $Q$ means that Rayleigh scattering polarizes perpendicular to the scattering plane, which, for single scattering, corresponds to the principal plane for this geometry.

The second row of the figure shows the same simulation but with an underlying ocean surface, which is modelled according to Mishchenko and Travis (1997) (bpdf_tsang). The wind speed was set to $2 \mathrm{~m} \mathrm{~s}^{-1}$. $I$ and $Q$ clearly show the sun glint, which has a maximum at a viewing angle of about $-30^{\circ}$ and is highly polarized. The intensity of the sun-glint increases with increasing wavelength since the incoming radiance at the surface becomes less diffuse when there is less Rayleigh scattering in the atmosphere.

The third row shows the result for desert aerosol as defined in the OPAC database (aerosol_species_file desert), with an underlying Lambertian surface albedo of 0.3 . I shows a backscatter peak at 670 and $865 \mathrm{~nm}$. $Q$ looks similar to Rayleigh scattering; however, there are differences mainly around the backscatter region. At wavelengths of 670 and $865 \mathrm{~nm}, Q$ has a minimum in the exact backscatter direction and becomes positive for viewing angles around this direction.

The fourth row shows a simulation including a water cloud (wc_properties mie) in $2-3 \mathrm{~km}$ altitude with an optical thickness of 10 and an effective droplet radius of $10 \mu \mathrm{m}$. $I$ and $Q$ show the glory about the backscatter direction and the rainbow at a viewing angle of about $-10^{\circ}$ corresponding to a scattering angle of $140^{\circ}$. In $Q$ the rainbow is more pronounced than in $I$ because $Q$ is less affected by multiple scattering. The angular resolution shown here is not sufficient to separate the glory from the backscattering peak in $I$. The sign of $Q$ in the rainbow region is the same as for Rayleigh scattering, whereas it is opposite in the glory region, which means that the rainbow is polarized perpendicular to the scattering plane, whereas the glory is polarized parallel to the scattering plane.

The last two rows show simulations with ice clouds, where we have used the yang2013 parameterization. An ice cloud layer with an optical thickness of 2 was included at an altitude from $9-10 \mathrm{~km}$. The selected habit was solid_column and we performed simulations for smooth crystals and for severely rough crystals. The effective crystal radius in both simulations is $30 \mu \mathrm{m}$. The smooth crystals show a backscatter peak in $I$ and a positive $Q$ about the backscatter direction. Also there are some smaller features in $I$ and $Q$. The radiances ( $I$ and $Q$ ) for rough crystals are smooth functions of viewing angle. This different behaviour has been used to determine the fraction of smooth crystals in ice clouds from POLDER measurements (Cole et al., 2014). 

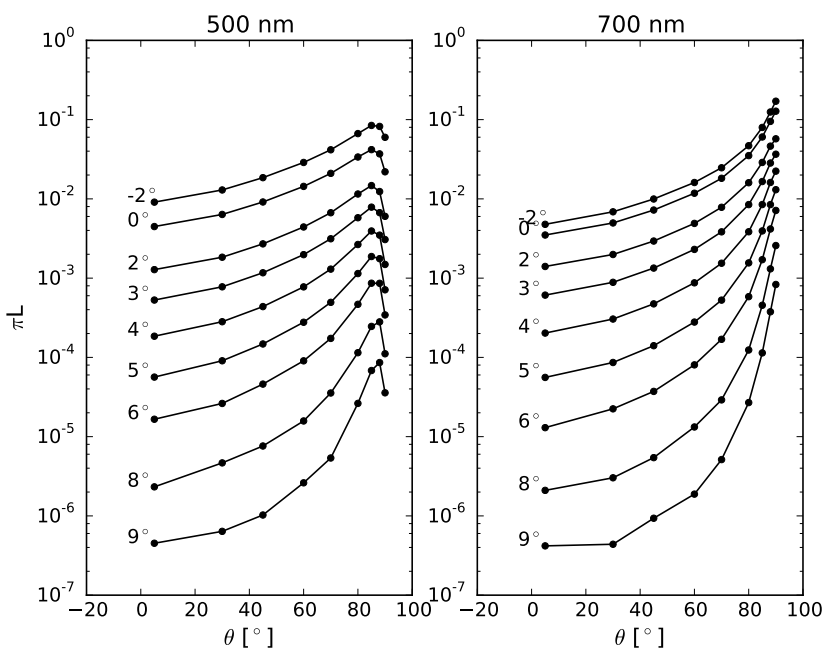

Figure 11. Twilight radiance at 500 and $700 \mathrm{~nm}$ calculated using fully spherical geometry for the US-standard atmosphere. The lines are for different solar depression angles. The $x$ axis corresponds to the viewing zenith angle.

\subsection{Fully spherical geometry}

MYSTIC can be operated in fully spherical geometry (mc_spherical 1D). The implementation of 1-D spherical geometry is described in Emde and Mayer (2007) where it has been used to simulate radiation in the umbral shadow of a solar eclipse. A comparison to measurements during the total eclipse in Greece in March 2006 (Kazantzidis et al., 2007) showed a very good agreement for modelled and measured UV irradiance, which decreased during totality by 2 to 3 orders of magnitude depending on wavelength.

Fully spherical geometry has also been used to simulate actinic fluxes at high solar zenith angles up to $92^{\circ}$ (Suminska-Ebersoldt et al., 2012).

Another interesting application is the simulation of polarized radiance at the surface at twilight, because polarized radiance measurements at twilight can be used to retrieve aerosol optical properties (e.g. Saito and Iwabuchi, 2015).

As an example we calculated polarized clear-sky radiances for solar depression angles up to $9^{\circ}$ for the US-standard atmosphere and default Rayleigh-scattering and absorption settings. Figure 11 shows the result as a function of viewing zenith angle. The relative azimuth angle between sun and observer is $0^{\circ}$, which means that the observer looks into the direction of the sun. We see that the intensity decreases by about 4 orders of magnitude for solar depression angles between $0^{\circ}$ (sun at horizon) and $9^{\circ}$ ( $\operatorname{sun} 9^{\circ}$ below horizon). The degree of polarization (not shown) at a viewing angle of $5^{\circ}$ is more than $90 \%$. All results agree to published results by Blättner et al. (1974), which indicates that fully spherical geometry works correctly in MYSTIC.

\section{Summary}

We have presented the libRadtran software package (version 2.0.1), which is a comprehensive and powerful collection of tools for radiative transfer simulations of the Earth's atmosphere. It is user-friendly, well-documented, and is widely used in the scientific community. We have described various new features and parameterizations, which have been included after the first publication of libRadtran in 2005. New features are for example a vector radiative transfer solver and a solver for rotational Raman scattering. The package includes state-of-the-art parameterizations for aerosol and ice cloud optical properties and a newly developed efficient absorption parameterization.

\section{Code availability}

The libRadtran package was initiated about 20 years ago and is still under continuous development. Regularly updated versions of the package are available from http://www. libradtran.org.

The website includes all released versions of the package. The latest release is version 2.0.1 and includes the source code, example input files, several tests, and the graphical user interface. Additional data packages containing optical properties of clouds and aerosols and the REPTRAN gas absorption parameterization are also available. The 1-D version of MYSTIC is part of the libRadtran public release. Please note that the 3-D version of MYSTIC is not part of the libRadtran public release, it is available in joint projects. 


\section{Appendix A: Ice crystal optical properties parameterizations}

The parameterization yang2013 is based on the singlescattering data by Yang et al. (2013). It is available for nine habits and three roughness parameters. It includes full phase matrices for the spectral range from $200 \mathrm{~nm}$ to $99 \mu \mathrm{m}$. The hey (Hong, Emde, Yang) parameterization is available for six individual smooth habits and includes the full phase matrices for the wavelength region from 0.2 to $5 \mu \mathrm{m}$. The singlescattering properties for the six ice crystal habits have been generated by Hong Gang based on the improved geometrical optics method (IGOM), the same which is applied in Yang et al. (2013).

In order to obtain bulk-scattering properties (required by the RTE solver), the single-scattering properties need to be integrated over the particle size distribution. In reality the size distributions are highly variable, for radiative transfer simulations they are often approximated by simple gamma distributions (e.g. Evans, 1998; Heymsfield et al., 2002; Baum et al., 2005a, b) or bi-modal gamma distributions (Mitchell et al., 1996a; Ivanova et al., 2001). We assume a gamma size distribution to compute the bulk-scattering properties as for the water cloud properties (compare Eq. 4):

$n\left(r_{e}\right)=N r_{e}^{\frac{1}{b}-3} \exp \left(-\frac{r_{e}}{a b}\right)$

Here $r_{e}$ is a measure of the particle size (the radius in case of spherical particles) and $N$ is the normalization constant so that the integral over the distribution yields the number of particles in a unit volume. For spherical particles the parameters $a$ and $b$ correspond to the effective radius $r_{\text {eff }}$ and to the effective variance $v_{\text {eff }}$, respectively. Typical values of cirrus cloud size distributions for $b$ are in the range between 0.1 and 0.5 (Evans, 1998; Heymsfield et al., 2002). In the following we take a fixed value of $b=0.25$. We define the effective particle size $r_{e}(L)$ for an individual ice crystal as follows (Yang et al., 2005):

$r_{e}(L)=\frac{3}{4} \frac{V(L)}{A(L)}$

Here $L$ is the maximum dimension of a nonspherical ice crystal and $A$ and $V$ are the mean projected area and the volume of the particle, respectively. $2 r_{e}(L)$ corresponds to the "effective distance", i.e. the representative distance a photon travels through an ice crystal without experiencing internal reflections and refraction (Mitchell et al., 1996b). The effective radius of a size distribution is generally defined as

$r_{\text {eff }}=\frac{3}{4} \frac{\int_{L_{\min }}^{L_{\max }} V(L) n(L) \mathrm{d} L}{\int_{L_{\min }}^{L_{\max }} A(L) n(L) \mathrm{d} L}$.

In order to obtain bulk-scattering properties which can be used for radiative transfer calculations, we pre-calculate bulk optical properties on a specified equidistant effective radius grid including values from 5 to $90 \mu \mathrm{m}$ in steps of $5 \mu \mathrm{m}$. Now using Eq. (A3) we iteratively find the parameter $a$ of the size distribution, which results in the desired effective radius. The bulk optical properties are then calculated by integration over the gamma distributions with the parameters $b=0.25$ and the iteratively obtained $a$ depending on the effective radius. libRadtran requires the extinction coefficient normalized to $1 \mathrm{~g} \mathrm{~m}^{-3}$ ice:

$\left\langle\beta_{\text {ext }}\left(r_{\text {eff }}\right)\right\rangle=\frac{\int_{L_{\min }}^{L_{\max }} A(L) Q_{\text {ext }}(L) n(L) \mathrm{d} L}{\rho \int_{L_{\min }}^{L_{\max }} V(L) n(L) \mathrm{d} L}$.

Here $Q_{\text {ext }}(L)$ is the extinction efficiency, $\rho$ is the density of ice, and $n(L)$ is the gamma size distribution which corresponds to the effective radius $r_{\text {eff. }}$ The single-scattering albedo $\left\langle\omega_{0}\right\rangle$ is calculated as follows:

$\left\langle\omega_{0}\left(r_{\mathrm{eff}}\right)\right\rangle=\frac{\int_{L_{\min }}^{L_{\max }} A(L) \omega_{0}(L) Q_{\mathrm{ext}}(L) n(L) \mathrm{d} L}{\int_{L_{\min }}^{L_{\max }} A(L) Q_{\mathrm{ext}}(L) n(L) \mathrm{d} L}$.

Finally, libRadtran requires the phase matrix $\left\langle P\left(r_{\text {eff }}\right)\right\rangle$, which is computed according to the following equation for each scattering angle $\theta$ and for six matrix elements (denoted by index $i$ ) needed to describe the scattering process by randomly oriented nonspherical particles (see e.g. van de Hulst, 1981))

$$
\begin{aligned}
& \left\langle P\left(r_{\mathrm{eff}}, i, \theta\right)\right\rangle= \\
& \frac{\int_{L_{\min }}^{L_{\max }} A(L) P(L, i, \theta) \omega_{0}(L) Q_{\mathrm{ext}}(L) n(L) \mathrm{d} L}{A(L) \int_{L_{\min }}^{L_{\max }} \omega_{0}(L) Q_{\mathrm{ext}}(L) n(L) \mathrm{d} L} .
\end{aligned}
$$

Optical properties for a general habit mixture ghm have also been calculated for the hey parameterization following the mixing "recipe" suggested by Baum et al. (2005b).

\section{Appendix B: Description of TZS solver}

This solver is based on the zero-scattering approximation and can be used to calculate clear-sky or "black cloud" radiances at the TOA in the thermal spectral range. Without scattering the formal solution of the RTE for the upward intensity (radiance) at TOA $I_{v}(\tau=0, \mu, \phi)$ at a given frequency $v$ reduces to

$$
\begin{aligned}
I_{v}(\tau=0, \mu, \phi) & =I_{v}\left(\tau^{*}, \mu, \phi\right) \exp \left(-\tau^{*} / \mu\right) \\
& +\int_{0}^{\tau^{*}} \frac{\mathrm{d} \tau}{\mu} B_{v}(\tau) \exp (-\tau / \mu) .
\end{aligned}
$$

Here we used the (vertical) absorption optical thickness $\tau$ measured from top of atmosphere as the vertical coordinate such that $\tau=0$ at TOA and $\tau=\tau^{*}$ at the surface. Variables $\mu$ and $\phi$ denote the cosine of the zenith angle and the azimuth 
angle, respectively. Planck's function at a given frequency $v$ is represented by $B_{v}(\tau)$ and its temperature dependence is contained implicitly in $\tau$.

The first term on the right-hand side in Eq. (B1) represents the contribution of the surface and the second one the contribution of the atmosphere. The surface contribution can be written as

$$
\begin{aligned}
& I_{\nu}\left(\tau^{*}, \mu, \phi\right)=\epsilon_{s} B_{v}\left(\tau^{*}\right) \\
& \quad+2\left(1-\epsilon_{s}\right) \int_{0}^{1} \int_{0}^{\tau^{*}} B_{v}(\tau) \exp \left(-\left(\tau^{*}-\tau\right) / \mu\right) \mathrm{d} \tau \mathrm{d} \mu,
\end{aligned}
$$

with the first term representing the emission of the surface ( $\epsilon_{s}=$ surface emissivity) and the second one the reflection at the surface of the radiation emitted by the atmosphere toward the surface. The factor 2 comes from the integration over the azimuth angle $\phi$.

Under the approximation of Planck's function $B_{v}(\tau)$ as a piecewise linear function in $\tau$ between two consecutive levels, both integrals can be solved as a function of the exponential integral $\operatorname{Ei}(x)=\int_{-\infty}^{-x} e^{-y} / y \mathrm{~d} y$. 


\section{The Supplement related to this article is available online at doi:10.5194/gmd-9-1647-2016-supplement.}

Acknowledgements. Numerous colleagues have contributed with software and comments to the package. We would like to thank K. Stamnes, W. Wiscombe, S. C. Tsay, and K. Jayaweera (disort), F. Evans (polradtran), S. Kato (correlated-k distribution), J.-M. Vandenberghe, F. Hendrick, and M. V. Roozendael (sdisort), T. Charlock, Q. Fu, and F. Rose (Fu and Liou code), D. Kratz (AVHRR routines), B. A. Baum, P. Yang, L. Bi, H. Gang, J. Key, B. Reinhardt, and A. Gonzales (ice cloud optical properties), P. Ricchiazzi (LOWTRAN/SBDART gas absorption), M. Hess (OPAC aerosol database), W. Wiscombe, C. F. Bohren, and D. Huffman (Mie codes), M. Mishchenko (water reflectance matrix), O. Engelsen (implementation of ozone cross sections), the ARTS community and Franz Schreier (line-by-line models), and J. Betcke (implementation of King Byrne equation). Thanks to all users for feedback and contributions, which helped to improve the software over the years. Thanks also to L. Scheck for providing the simulated satellite image shown in Sect. 11.2. Finally, we thank two anonymous reviewers and the topical editor K. Gierens for their useful comments. Part of the libRadtran development was funded by ESA (ESASLight projects AO/1-5433/07/NL/HE, $\mathrm{AO} / 1-6607 / 10 / \mathrm{NL} / \mathrm{LvH})$.

Edited by: K. Gierens

\section{References}

Ackerman, M.: UV-solar radiation related to mesospheric processes, edited by: Fiocco, G., Astrophysics and Space Science Library, Springer Netherlands, 1971.

Alexandrov, M. D., Cairns, B., Emde, C., Ackerman, A. S., and van Diedenhoven, B.: Accuracy assessments of cloud droplet size retrievals from polarized reflectance measurements by the research scanning polarimeter, Remote Sens. Environ., 125, 92 111, doi:10.1016/j.rse.2012.07.012, 2012.

Anderson, G., Clough, S., Kneizys, F., Chetwynd, J., and Shettle, E.: AFGL atmospheric constituent profiles $(0-120 \mathrm{~km})$, Tech. Rep. AFGL-TR-86-0110, Air Force Geophys. Lab., Hanscom Air Force Base, Bedford, Mass., 1986.

Baldauf, M., Seifert, A., Förstner, J., Majewski, D., Raschendorfer, M., and Reinhardt, T.: Operational convective-scale numerical weather prediction with the COSMO model: description and sensitivities, Mon. Weather Rev., 139, 3887-3905, 2011.

Bass, A. M. and Paur, R. J.: The ultraviolet cross-section of ozone, I, The measurements, in: Atmospheric Ozone: Proceedings of the Quadrennial Ozone Symposium, edited by: Zerefos, C. S. and Ghazi, A., 601-606, D. Reidel, Norwell, Mass., 1985.

Baum, B., Heymsfield, A., Yang, P., and Bedka, S.: Bulk scattering models for the remote sensing of ice clouds. Part 1: Microphysical data and models, J. Appl. Meteorol., 44, 1885-1895, 2005a.

Baum, B., Yang, P., Heymsfield, A., Platnick, S., King, M., Hu, Y.X., and Bedka, S.: Bulk scattering models for the remote sensing of ice clouds. Part 2: Narrowband models, J. Appl. Meteorol., 44, 1896-1911, 2005b.
Baum, B. A., Yang, P., Heymsfield, A. J., Bansemer, A., Merrelli, A., Schmitt, C., and Wang, C.: Ice cloud bulk singlescattering property models with the full phase matrix at wavelengths from 0.2 to $100 \mu \mathrm{m}$, J. Quant. Spectrosc. Ra., 146, 123 139, doi:10.1016/j.jqsrt.2014.02.029, 2014.

Blättner, W. G., Horak, H. G., Collins, D. G., and Wells, M. B.: Monte Carlo Studies of the Sky Radiation of Twilight, Appl. Optics, 13, 534-547, 1974.

Bodhaine, B. A., Wood, N. B., Dutton, E. G., and Slusser, J. R.: On Rayleigh optical depth calculations, J. Atmos. Ocean Tech., 16, 1854-1861, 1999.

Bogumil, K., Orphal, J., Voigt, S., Spietz, P., Fleischmann, O. C., Vogel, A., Hartmann, M., Kromminga, H., Bovensmann, H., Frerick, J., and Burrows, J. P.: Measurements of molecular absorption spectra with the SCIAMACHY pre-flight model: instrument characterization and reference data for atmospheric remotesensing in the 230-2380 nm region, J. Photochem. Photobio. A: Chem., 157, 167-184, 2003.

Bohren, C. F. and Huffman, D. R.: Absorption and Scattering of Light by Small Particles, John Wiley \& Sons, New York, 1983.

Buehler, S., John, V., Kottayil, A., Milz, M., and Eriksson, P.: Efficient radiative transfer simulations for a broadband infrared radiometer - combining a weighted mean of representative frequencies approach with frequency selection by simulated annealing, J. Quant. Spectrosc. Ra., 111, 602-615, 2010.

Bugliaro, L., Zinner, T., Keil, C., Mayer, B., Hollmann, R., Reuter, M., and Thomas, W.: Validation of cloud property retrievals with simulated satellite radiances: a case study for SEVIRI, Atmos. Chem. Phys., 11, 5603-5624, doi:10.5194/acp-11-5603-2011, 2011.

Buras, R. and Mayer, B.: Efficient unbiased variance reduction techniques for Monte Carlo simulations of radiative transfer in cloudy atmospheres: The solution, J. Quant. Spectrosc. Ra., 112, 434-447, 2011.

Buras, R., Dowling, T., and Emde, C.: New secondary-scattering correction in DISORT with increased efficiency for forward scattering, J. Quant. Spectrosc. Ra., 112, 2028-2034, 2011.

Burrows, J. P., Dehn, A., Deters, B., Himmelmann, S., Richter, A., Voigt, S., and Orphal, J.: Atmospheric remote-sensing reference data from GOME: Part 1. Temperature-dependent absorption cross sections of $\mathrm{NO}_{2}$ in the 231-794 nm range, J. Quant. Spectrosc. Ra., 60, 1025-1031, 1998.

Cahalan, R. F., Oreopoulos, L., Marshak, A., Evans, K. F., Davis, A., Pincus, R., Yetzer, K., Mayer, B., Davies, R., Ackerman, T. P., Barker, H. W., Clothiaux, E. E., Ellingson, R. G., Garay, M. J., Kassianov, E., Kinne, S., Macke, A., O'Hirok, W., Partain, P. T., Prigarin, S. M., Rublev, A. N., Stephens, G. L., Szczap, F., Takara, E. E., Varnai, T., Wen, G., and Zhuraleva, T. B.: The International Intercomparison of 3D Radiation Codes (I3RC): Bringing together the most advanced radiative transfer tools for cloudy atmospheres, B. Am. Meteorol. Soc., 86, 1275-1293, 2005.

Cantrell, C. A., Davidson, J. A., McDaniel, A. H., Shetter, R. E., and Calvert, J. G.: Temperature-dependent formaldehyde cross sections in the near-ultraviolet spectral region, J. Phys. Chem., 94, 3902-3908, 1990.

Chahine, M.: Remote sounding of cloudy atmospheres, I, The single cloud layer, J. Atmos. Sci., 31, 233-243, 1974. 
Chandrasekhar, S.: Radiative transfer, Oxford Univ. Press, UK, 1950.

Clarisse, L., Prata, F., Lacour, J.-L., Hurtmans, D., Clerbaux, C., and Coheur, P.-F.: A correlation method for volcanic ash detection using hyperspectral infrared measurements, Geophys. Res. Lett., 37, L19806, doi:10.1029/2010GL044828, 2010.

Clarisse, L., Coheur, P.-F., Prata, F., Hadji-Lazaro, J., Hurtmans, D., and Clerbaux, C.: A unified approach to infrared aerosol remote sensing and type specification, Atmos. Chem. Phys., 13, 21952221, doi:10.5194/acp-13-2195-2013, 2013.

Clerbaux, C., Boynard, A., Clarisse, L., George, M., Hadji-Lazaro, J., Herbin, H., Hurtmans, D., Pommier, M., Razavi, A., Turquety, S., Wespes, C., and Coheur, P.-F.: Monitoring of atmospheric composition using the thermal infrared IASI/MetOp sounder, Atmos. Chem. Phys., 9, 6041-6054, doi:10.5194/acp-9-6041-2009, 2009.

Cole, B. H., Yang, P., Baum, B. A., Riedi, J., and C.-Labonnote, L.: Ice particle habit and surface roughness derived from PARASOL polarization measurements, Atmos. Chem. Phys., 14, 37393750, doi:10.5194/acp-14-3739-2014, 2014.

Cox, C. and Munk, W.: Measurement of the roughness of the sea surface from photographs of the sun's glitter, J. Opt. Soc. Am., 44, 838-850, 1954a.

Cox, C. and Munk, W.: Statistics of the sea surface derived from sun glitter, J. Mar. Res., 13, 198-227, 1954b.

Dahlback, A. and Stamnes, K.: A new spherical model for computing the radiation field available for photolysis and heating at twilight, Planet. Space Sci., 39, 671-683, 1991.

Daumont, D., Brion, J., Charbonnier, J., and Malicet, J.: Ozone UV spectroscopy I: Absorption cross-sections at room temperature, J. Atmos. Chem., 15, 145-155, 1992.

Degünther, M. and Meerkötter, R.: Influence of inhomogeneous surface albedo on UV irradiance: Effect of a stratus cloud, J. Geophys. Res., 105, 22755-22761, 2000.

Deschamps, P.-Y., Breon, F.-M., Leroy, M., Podaire, A., Bricaud, A., Buriez, J.-C., and Seze, G.: The POLDER mission: instrument characteristics and scientific objectives, IEEE T. Geosci. Remote Sens., 32, 598-615, doi:10.1109/36.297978, 1994.

Drusch, M., Bello, U. D., Carlier, S., Colin, O., Fernandez, V., Gascon, F., Hoersch, B., Isola, C., Laberinti, P., Martimort, P., Meygret, A., Spoto, F., Sy, O., Marchese, F., and Bargellini, P.: Sentinel-2: ESA's Optical High-Resolution Mission for \{GMES\} Operational Services, Remote Sens. Environ., 120, 25-36, doi:10.1016/j.rse.2011.11.026, 2012.

Ehret, G., Kiemle, C., Wirth, M., Amediek, A., Fix, A., and Houweling, S.: Space-borne remote sensing of $\mathrm{CO}_{2}, \mathrm{CH}_{4}$, and $\mathrm{N}_{2} \mathrm{O}$ by integrated path differential absorption lidar: a sensitivity analysis, Appl. Phys. B, 90, 593-608, doi:10.1007/s00340-0072892-3, 2008.

Emde, C. and Mayer, B.: Simulation of solar radiation during a total eclipse: a challenge for radiative transfer, Atmos. Chem. Phys., 7, 2259-2270, doi:10.5194/acp-7-2259-2007, 2007

Emde, C., Buras, R., Mayer, B., and Blumthaler, M.: The impact of aerosols on polarized sky radiance: model development, validation, and applications, Atmos. Chem. Phys., 10, 383-396, doi:10.5194/acp-10-383-2010, 2010.

Emde, C., Buras, R., and Mayer, B.: ALIS: An efficient method to compute high spectral resolution polarized solar radiances using the Monte Carlo approach, J. Quant. Spectrosc. Ra., 112, 16221631, 2011.

Emde, C., Barlakas, V., Cornet, C., Evans, F., Korkin, S., Ota, Y., Labonnote, L. C., Lyapustin, A., Macke, A., Mayer, B., and Wendisch, M.: IPRT polarized radiative transfer model intercomparison project - Phase A, J. Quant. Spectrosc. Ra., 164, 8-36, doi:10.1016/j.jqsrt.2015.05.007, 2015.

Eriksson, P., Buehler, S. A., Davis, C. P., Emde, C., and Lemke, O.: ARTS, the atmospheric radiative transfer simulator, Version 2, J. Quant. Spectrosc. Ra., 112, 1551-1558, 2011.

Evans, K. F.: The spherical harmonics discrete ordinate method for three-dimensional atmospheric radiative transfer, J. Atmos. Sci., 55, 429-446, 1998.

Evans, K. F. and Stephens, G. L.: A new polarized atmospheric radiative transfer model, J. Quant. Spectrosc. Ra., 46, 413-423, 1991.

Eyre, J. and Menzel, P.: Retrieval of Cloud Parameters from Satellite Sounder Data: A Simulation Study, J. Appl. Meteorol., 28, 267-275, 1989.

Forster, L., Emde, C., Mayer, B., and Unterstrasser, S.: Effects of Three-Dimensional Photon Transport on the Radiative Forcing of Realistic Contrails, J. Atmos. Sci., 69, 2243-2255, 2012.

Forster, P. M., Fomichev, V. I., Rozanov, E., Cagnazzo, C., Jonsson, A. I., Langematz, U., Fomin, B., Iacono, M. J., Mayer, B., Mlawer, E., Myhre, G., Portmann, R. W., Akiyoshi, H., Falaleeva, V., Gillett, N., Karpechko, A., Li, J., Lemennais, P., Morgenstern, O., Oberlaender, S., Sigmond, M., and Shibata, K.: Evaluation of radiation scheme performance within chemistry climate models, J. Geophys. Res., 116, D10302, doi:10.1029/2010JD015361, 2011.

$\mathrm{Fu}, \mathrm{Q}$.: An accurate parameterization of the solar radiative properties of cirrus clouds for climate models, J. Climate, 9, 2058 2082, 1996.

$\mathrm{Fu}, \mathrm{Q}$. and Liou, K.: On the correlated k-distribution method for radiative transfer in nonhomogeneous atmospheres, J. Atmos. Sci., 49, 2139-2156, 1992.

$\mathrm{Fu}, \mathrm{Q}$. and Liou, K.: Parameterization of the radiative properties of cirrus clouds, J. Atmos. Sci., 50, 2008-2025, 1993.

Fu, Q., Yang, P., and Sun, W. B.: An accurate parameterization of the infrared radiative properties of cirrus clouds for climate models, J. Climate, 11, 2223-2237, 1998.

Gangale, G., Prata, A. J., and Clarisse, L.: The infrared spectral signature of volcanic ash determined from high-spectral resolution satellite measurements, Remote Sens. Environ., 114, 414-425, 2010.

Gasteiger, J., Groß, S., Freudenthaler, V., and Wiegner, M.: Volcanic ash from Iceland over Munich: mass concentration retrieved from ground-based remote sensing measurements, Atmos. Chem. Phys., 11, 2209-2223, doi:10.5194/acp-11-22092011, 2011.

Gasteiger, J., Emde, C., Mayer, B., Buehler, S. A., and Lemke, O.: Representative wavelengths absorption parameterization applied to satellite channels and spectral bands, J. Quant. Spectrosc. Ra., 148, 99-115, 2014.

Greenblatt, G. D., Orlando, J. J., Burkholder, J. B., and Ravishankara, A. R.: Absorption measurements of oxygen between 330 and 1140 nm, J. Geophys. Res., 95, 18577-18582, 1990.

Guanter, L., Alonso, L., Gómez-Chova, L., Meroni, M., Preusker, R., Fischer, J., and Moreno, J.: Developments for vegetation fluo- 
rescence retrieval from spaceborne high-resolution spectrometry in the $\mathrm{O}_{2}-\mathrm{A}$ and $\mathrm{O}_{2}-\mathrm{B}$ absorption bands, J. Geophys. Res., 115, 2463-2479, doi:10.1029/2009JD013716, 2010.

Hansen, J. E. and Travis, L. D.: Light scattering in planetary atmospheres, Space Sci. Rev., 16, 527-610, 1974.

Hapke, B.: Theory of reflectance and emittance spectroscopy, New York: Cambridge University Press, 1993.

Hess, M., Koepke, P., and Schult, I.: Optical Properties of Aerosols and Clouds: The Software Package OPAC, B. Am. Meteorol. Soc., 79, 831-844, 1998.

Heymsfield, A. J., Bansemer, A., Field, P. R., Durden, S. L., Stith, J. L., Dye, J. E., Hall, W., and Grainger, A. C.: Observations and Parameterizations of Particle Size Distributions in Deep Tropical Cirrus and Stratiform Precipitating Clouds: Results from In Situ Observations in TRMM Field Campaigns, J. Atmos. Sci., 59, 3457-3491, 2002.

Heymsfield, A. J., Schmitt, C., and Bansemer, A.: Ice cloud particle size distributions and pressure dependent terminal velocities from in situ observations at temperatures from $0^{\circ}$ to $-86^{\circ} \mathrm{C}, \mathrm{J}$. Atmos. Sci., 70, 4123-4154, 2013.

Hilton, F., Armante, R., August, T., Barnet, C., Bouchard, A., Camy-Peyret, C., Capelle, V., Clarisse, L., Clerbaux, C., Coheur, P.-F., Collard, A., Crevoisier, C., Dufour, G., Edwards, D., Faijan, F., Fourrié, N., Gambacorta, A., Goldberg, M., Guidard, V., Hurtmans, D., Illingworth, S., Jacquinet-Husson, N., Kerzenmacher, T., Klaes, D., Lavanant, L., Masiello, G., Matricardi, M., McNally, A., Newman, S., Pavelin, E., Payan, S., Péquignot, E., Peyridieu, S., Phulpin, T., Remedios, J., Schlüssel, P., Serio, C., Strow, L., Stubenrauch, C., Taylor, J., Tobin, D., Wolf, W., and Zhou, D.: Hyperspectral Earth Observation from IASI: Five Years of Accomplishments, B. Am. Meteorol. Soc., 93, 347-370, doi:10.1175/BAMS-D-11-00027.1, 2011.

$\mathrm{Hu}$, Y. X. and Stamnes, K.: An accurate parameterization of the radiative properties of water clouds suitable for use in climate models, J. Climate, 6, 728-742, 1993.

Ivanova, D., Mitchell, D. L., Arnott, W. P., and Poellot, M.: A GCM parameterization for bimodal size spectra and ice mass removal rates in mid-latitude cirrus clouds, Atmos. Res., 59-60, 89-113, 2001.

Kato, S., Ackerman, T. P., Mather, J. H., and Clothiaux, E.: The $k-$ distribution method and correlated- $k$ approximation for a shortwave radiative transfer model, J. Quant. Spectrosc. Ra., 62, 109121, 1999.

Kazantzidis, A., Bais, A. F., Emde, C., Kazadzis, S., and Zerefos, C. S.: Attenuation of global ultraviolet and visible irradiance over Greece during the total solar eclipse of 29 March 2006, Atmos. Chem. Phys., 7, 5959-5969, doi:10.5194/acp-7-5959-2007, 2007.

Key, J. R., Yang, P., Baum, B. A., and Nasiri, S. L.: Parameterization of shortwave ice cloud optical properties for various particle habits, J. Geophys. Res., 107, AAC 7-1-AAC 7-10, doi:10.1029/2001JD000742, 2002.

Klinger, C. and Mayer, B.: Three-dimensional Monte Carlo calculation of atmospheric thermal heating rates, J. Quant. Spectrosc. Ra., 144, 123-136, doi:10.1016/j.jqsrt.2014.04.009, 2014.

Koepke, P., Gasteiger, J., and Hess, M.: Technical Note: Optical properties of desert aerosol with non-spherical mineral particles: data incorporated to OPAC, Atmos. Chem. Phys., 15, 59475956, doi:10.5194/acp-15-5947-2015, 2015.
Kokhanovsky, A. A., Budak, V. P., Cornet, C., Duan, M., Emde, C., Katsev, I. L., Klyukov, D. A., Korkin, S. V., C-Labonnote, L., Mayer, B., Min, Q., Nakajima, T., Ota, Y., Prikhach, A. S., Rozanov, V. V., Yokota, T., and Zege, E. P.: Benchmark results in vector atmospheric radiative transfer, J. Quant. Spectrosc. Ra., 111, 1931-1946, 2010a.

Kokhanovsky, A. A., Deuzé, J. L., Diner, D. J., Dubovik, O., Ducos, F., Emde, C., Garay, M. J., Grainger, R. G., Heckel, A., Herman, M., Katsev, I. L., Keller, J., Levy, R., North, P. R. J., Prikhach, A. S., Rozanov, V. V., Sayer, A. M., Ota, Y., Tanré, D., Thomas, G. E., and Zege, E. P.: The inter-comparison of major satellite aerosol retrieval algorithms using simulated intensity and polarization characteristics of reflected light, Atmos. Meas. Tech., 3, 909-932, doi:10.5194/amt-3-909-2010, 2010 b.

Kostka, P. M., Weissmann, M., Buras, R., Mayer, B., and Stiller, O.: Observation Operator for Visible and Near-Infrared Satellite Reflectances, J. Atm. Ocean Technol., 31, 1216-1233, doi:10.1175/JTECH-D-13-00116.1, 2014.

Kotchenova, S. Y., Vermote, E. F., Matarrese, R., and Klemm, F. J.: Validation of a vector version of the $6 \mathrm{~S}$ radiative transfer code for atmospheric correction of satellite data. Part I: Path radiance, Appl. Optics, 45, 6762-6774, 2006.

Kreuter, A., Buras, R., Mayer, B., Webb, A., Kift, R., Bais, A., Kouremeti, N., and Blumthaler, M.: Solar irradiance in the heterogeneous albedo environment of the Arctic coast: measurements and a 3-D model study, Atmos. Chem. Phys., 14, 59896002, doi:10.5194/acp-14-5989-2014, 2014.

Kylling, A. and Stamnes, K.: Efficient yet accurate solution of the linear transport equation in the presence of internal sources: the exponential-linear-in-depth approximation, J. Comput. Phys., 102, 265-276, 1992.

Kylling, A., Stamnes, K., and Tsay, S.-C.: A reliable and efficient two-stream algorithm for spherical radiative transfer: documentation of accuracy in realistic layered media, J. Atmos. Chem., 21, 115-150, 1995.

Kylling, A., Mayer, B., and Blumthaler, M.: Technical Note: A new discrete ordinate first-order rotational Raman scattering radiative transfer model - implementation and first results, Atmos. Chem. Phys., 11, 10471-10485, doi:10.5194/acp-11-10471-2011, 2011.

Kylling, A., Buras, R., Eckhardt, S., Emde, C., Mayer, B., and Stohl, A.: Simulation of SEVIRI infrared channels: a case study from the Eyjafjallajökull April/May 2010 eruption, Atmos. Meas. Tech., 6, 649-660, doi:10.5194/amt-6-649-2013, 2013.

Kylling, A., Kristiansen, N., Stohl, A., Buras-Schnell, R., Emde, C., and Gasteiger, J.: A model sensitivity study of the impact of clouds on satellite detection and retrieval of volcanic ash, Atmos. Meas. Tech., 8, 1935-1949, doi:10.5194/amt-8-1935-2015, 2015.

Lee, D., Pitari, G., Grewe, V., Gierens, K., Penner, J., Petzold, A., Prather, M., Schumann, U., Bais, A., Berntsen, T., Iachetti, D., Lim, L., and Sausen, R.: Transport impacts on atmosphere and climate: Aviation, Atmos. Environ., 44, 4678-4734, doi:10.1016/j.atmosenv.2009.06.005, 2010.

Lohmann, S., Schillings, C., Mayer, B., and Meyer, R.: Long-term variability of solar direct and global radiation derived from \{IS$\mathrm{CCP}\}$ data and comparison with reanalysis data, Sol. Energy, 80, 1390-1401, doi:10.1016/j.solener.2006.03.004, 2006.

Lucht, W., Schaaf, C., and Strahler, A.: An algorithm for the retrieval of albedo from space using semiempirical 
BRDF models, IEEE T. Geosci. Remote Sens., 38, 977-998, doi:10.1109/36.841980, 2000.

Maignan, F., Breon, F.-M., and Lacaze, R.: Bidirectional reflectance of Earth targets: evaluation of analytical models using a large set of spaceborne measurements with emphasis on the Hot Spot, Remote Sens. Environ., 90, 210-220, doi:10.1016/j.rse.2003.12.006, 2004.

Malicet, J., Daumont, D., Charbonnier, J., Parisse, C., Chakir, A., and Brion, J.: Ozone UV spectroscopy. II. Absorption crosssections and temperature dependence, J. Atmos. Chem., 21, $263-$ 273, 1995

Martin, G. M., Johnson, D. W., and Spic, A.: The measurement and parameterization of effective radius of droplets in warm stratocumulus clouds, J. Atmos. Sci., 51, 1823-1842, 1994.

Mayer, B.: Radiative transfer in the cloudy atmosphere, European Physical Journal Conferences, 1, 75-99, 2009.

Mayer, B. and Kylling, A.: Technical note: The libRadtran software package for radiative transfer calculations - description and examples of use, Atmos. Chem. Phys., 5, 1855-1877, doi:10.5194/acp-5-1855-2005, 2005.

Mayer, B., Hoch, S. W., and Whiteman, C. D.: Validating the MYSTIC three-dimensional radiative transfer model with observations from the complex topography of Arizona's Meteor Crater, Atmos. Chem. Phys., 10, 8685-8696, doi:10.5194/acp-10-86852010, 2010.

Menzel, W., Smith, W., and Stewart, T.: Improved cloud motion wind vector and altitude assignment using VAS, J. Appl. Meteorol., 22, 377-384, 1983.

Miller, J. R., Berger, M., Goulas, Y., Jacquemoud, S., Louis, J., Mohammed, G., Moise, N., Moreno, J., Moya, I., Pedros, R., Verhoef, W., and Zarco-Tejada, P.: Development of a Vegetation Fluorescence Canopy Model, Tech. rep., ESA-ESTEC, Noordwijk, the Netherlands, available at: http://www.ias.csic.es/fluormod/ (last access: 6 June 2013), 2005.

Minschwaner, K., Anderson, G. P., Hall, L. A., and Yoshino, K.: Polynomial coefficients for calculating $\mathrm{O}_{2}$ Schumann-Runge cross sections at $0.5 \mathrm{~cm}^{-1}$ resolution, J. Geophys. Res., 97, 10103-10108, 1992.

Mishchenko, M. I. and Travis, L. D.: Satellite retrieval of aerosol properties over the ocean using polarization as well as intensity of reflected sunlight, J. Geophys. Res., 102, 16989-17013, 1997.

Mishchenko, M. I. and Travis, L. D.: Capabilities and limitations of a current Fortran implementation of the T-Matrix method for randomly oriented, rotationally symmetric scatterers, J. Quant. Spectrosc. Ra., 60, 309-324, 1998.

Mishchenko, M., Lacis, A., and Travis, L.: Errors induced by the neglect of polarization in radiance calculations for rayleighscattering atmospheres, J. Quant. Spectrosc. Ra., 51, 491-510, doi:10.1016/0022-4073(94)90149-X, 1994.

Mishchenko, M. I., Travis, L., and Lacis, A.: Scattering, Absorption, and Emission of Light by Small Particles, Cambridge University Press, 2002.

Mishchenko, M. I., Cairns, B., Kopp, G., Schueler, C. F., Fafaul, B. A., Hansen, J. E., Hooker, R. J., Itchkawich, T., Maring, H. B., and Travis, L. D.: Accurate Monitoring of Terrestrial Aerosols and Total Solar Irradiance: Introducing the Glory Mission, B. Am. Meteorol. Soc., 88, 677-691, doi:10.1175/BAMS-88-5-677, 2007
Mitchell, D. L., Chai, S. K., Liu, Y., Heymsfield, A. J., and Dong, Y.: Modeling Cirrus Clouds. Part I: Treatment of Bimodal Size Spectra and Case Study Analysis, J. Atmos. Sci., 53, 2952-2966, 1996a.

Mitchell, D. L., Macke, A., and Liu, Y.: Modeling Cirrus Clouds. Part II: Treatment of radiative properties, J. Atmos. Sci., 53, 2967-2988, 1996b.

Molina, L. T. and Molina, M. J.: Absolute absorption cross sections of ozone in the 185 to $350 \mathrm{~nm}$ wavelength range, J. Geophys. Res., 91, 14501-14508, 1986.

Nakajima, T. and Tanaka, M.: Effect of wind-generated waves on the transfer of solar radiation in the atmosphere-ocean system, $\mathrm{J}$. Quant. Spectrosc. Ra., 29, 521-537, 1983.

Nicolet, M.: On the molecular scattering in the terrestrial atmosphere: An empirical formula for its calculation in the homosphere, Planet. Space Sci., 32, 1467-1468, 1984.

Ogawa, S. and Ogawa, M.: Absorption cross sections of $\mathrm{O}_{2}$ (a 1Dg) and $\mathrm{O}_{2}$ (X 3Sg-) in the region from 1087 to $1700 \AA$, Can. J. Phys., 53, 1845-1852, 1975.

Painemal, D. and Zuidema, P.: Assessment of MODIS cloud effective radius and optical thickness retrievals over the Southeast Pacific with VOCALS-REx in situ measurements, J. Geophys. Res.-Atmos., 116, D24206, doi:10.1029/2011JD016155, 2011.

Penndorf, R.: Tables of the refractive index for standard air and the Rayleigh scattering coefficient for the spectral region between 0.2 and $20.0 \mu$ and their application to atmospheric optics, J. Opt. Soc. Am., 47, 176-182, 1957.

Pierluissi, J. H. and Peng, G.-S.: New molecular transmission band models for LOWTRAN, Opt. Eng., 24, 541-547, 1985.

Pollack, J. B., Toon, O. B., and Khare, B. N.: Optical properties of some terrestrial rocks and glasses, ICARUS, 19, 372-389, 1973.

Rahman, H., Pinty, B., and Verstraete, M. M.: Coupled surfaceatmosphere reflectance (CSAR) model 2. semiempirical surface model usable with NOAA advanced very high resolution radiometer data, J. Geophys. Res., 98, 20791-20801, 1993.

Rannou, P., Cours, T., Mouélic, S. L., Rodriguez, S., Sotin, C., Drossart, P., and Brown, R.: Titan haze distribution and optical properties retrieved from recent observations, Icarus, 208, 850 867, doi:10.1016/j.icarus.2010.03.016, 2010.

Reinhardt, B., Buras, R., Bugliaro, L., Wilbert, S., and Mayer, B.: Determination of circumsolar radiation from Meteosat Second Generation, Atmos. Meas. Tech., 7, 823-838, doi:10.5194/amt7-823-2014, 2014.

Ricchiazzi, P., Yang, S., Gautier, C., and Sowle, D.: SBDART: A research and Teaching software tool for plane-parallel radiative transfer in the Earth's atmosphere, B. Am. Meteorol. Soc., 79, 2101-2114, 1998.

Rinehart, R.: Radar for meteorologists, 5th Edn., Rinehart Publications, North Dakota, USA, 2010.

Roeckner, E., Arpe, K., Bengtsson, L., Christoph, M., Claussen, M., Dümenil, L., Esch, E., Giorgetta, M., Schlese, U., and Schulzweida, U.: The atmospheric general circulation model ECHAM-4: model description and simulation of present-day climate, Tech. rep., Max Planck-Institut für Meteorologie, Report No. 218, 1996.

Rothman, L. S., Jacquemart, D., Barbe, A., Benner, D. C., Birk, M., Brown, L. R., Carleer, M. R., Chackerian Jr., C., Chance, K., Coudert, L. H., Dana, V., Devi, V. M., Flaud, J., Gamache, R. R., Goldman, A., Hartmann, J., Jucks, K. W., Maki, A. G., 
Mandin, J., Massie, S. T., Orphal, J., Perrin, A., Rinsland, C. P., Smith, M. A. H., Tennyson, J., Tolchenov, R. N., Toth, R. A., Vander Auwera, J., Varanasi, P., and Wagner, G.: The HITRAN 2004 molecular spectroscopic database, J. Quant. Spectrosc. Ra., 96, 139-204, 2005.

Roujean, J.-L., Leroy, M., and Deschamps, P.: A bidirectional reflectance model of the Earth's surface for the correction of remote sensing data, J. Geophys. Res., 97, 20455-20468, 1992.

Saito, M. and Iwabuchi, H.: A new method of measuring aerosol optical properties from digital twilight photographs, Atmos. Meas. Tech., 8, 4295-4311, doi:10.5194/amt-8-4295-2015, 2015.

Schaaf, C. B., Gao, F., Strahler, A. H., Lucht, W., Li, X., Tsang, T., Strugnell, N. C., Zhang, X., Jin, Y., Muller, J.-P., Lewis, P., Barnsley, M., Hobson, P., Disney, M., Roberts, G., Dunderdale, M., Doll, C., d'Entremont, R. P., Hu, B., Liang, S., Privette, J. L., and Roy, D.: First operational BRDF, albedo nadir reflectance products from \{MODIS\}, Remote Sens. Environ., 83, 135-148, doi:10.1016/S0034-4257(02)00091-3, 2002.

Schreier, F.: Optimized evaluation of a large sum of functions using a three-grid approach, Comput. Phys. Commun., 174, 783-792, 2006.

Schreier, F. and Böttger, U.: MIRART, a line-by-line code for infrared atmospheric radiation computations incl. derivatives, Atmos. Ocean. Opt., 16, 262-268, 2003.

Schreier, F. and Kohlert, D.: Optimized implementations of rational approximations - a case study on the Voigt and complex error function, Comput. Phys. Commun., 179, 457-465, 2008.

Schulmann, T., Katurji, M., and Zawar-Reza, P.: Seeing through shadow: Modelling surface irradiance for topographic correction of Landsat ETM plus data, ISPRS J. Photogrammetry Rem. Sens., 99, 14-24, doi:10.1016/j.isprsjprs.2014.10.004, 2015.

Seckmeyer, G., Pissulla, D., Glandorf, M., Henriques, D., Johnsen, B., Webb, A., Siani, A.-M., Bais, A., Kjeldstad, B., Brogniez, C., Lenoble, J., Gardiner, B., Kirsch, P., Koskela, T., Kaurola, J., Uhlmann, B., Slaper, H., den Outer, P., Janouch, M., Werle, P., Groebner, J., Mayer, B., de la Casiniere, A., Simic, S., and Carvalho, F.: Variability of UV irradiance in Europe, Photochem. Photobiol., 84, 172-179, doi:10.1111/j.17511097.2007.00216.x, 2008.

Shettle, E.: Models of aerosols, clouds and precipitation for atmospheric propagation studies, in: Atmospheric propagation in the uv, visible, ir and mm-region and related system aspects, no. 454 in AGARD Conference Proceedings, 1989.

Smith, W. and Platt, C.: Intercomparison of radiosonde, groundbased laser, and satellite-deduced cloud heights, J. Appl. Meteorol., 17, 1796-1802, 1978.

Smith, W., Woolf, H., and Jacob, W.: A regression method for obtaining real-time temperature and geopotential height profiles from satellite spectrometer measurements and its application to Nimbus-3 SIRS observations, Mon. Weather Rev., 98, 604-611, 1970.

Stamnes, K., Tsay, S.-C., Wiscombe, W., and Jayaweera, K.: Numerically stable algorithm for discrete-ordinate-method radiative transfer in multiple scattering and emitting layered media, Appl. Optics, 27, 2502-2509, 1988.

Stamnes, K., Tsay, S.-C., Wiscombe, W., and Laszlo, I.: DISORT, a General-Purpose Fortran Program for Discrete-Ordinate-Method Radiative Transfer in Scattering and Emitting Layered Media: Documentation of Methodology, Tech. rep., Dept. of Physics and
Engineering Physics, Stevens Institute of Technology, Hoboken, NJ 07030, 2000

Suminska-Ebersoldt, O., Lehmann, R., Wegner, T., Grooß, J.-U., Hösen, E., Weigel, R., Frey, W., Griessbach, S., Mitev, V., Emde, C., Volk, C. M., Borrmann, S., Rex, M., Stroh, F., and von Hobe, $\mathrm{M}$.: $\mathrm{ClOOCl}$ photolysis at high solar zenith angles: analysis of the RECONCILE self-match flight, Atmos. Chem. Phys., 12, 13531365, doi:10.5194/acp-12-1353-2012, 2012.

Theys, N., Van Roozendael, M., Hendrick, F., Fayt, C., Hermans, C., Baray, J.-L., Goutail, F., Pommereau, J.-P., and De Mazière, M.: Retrieval of stratospheric and tropospheric BrO columns from multi-axis DOAS measurements at Reunion Island $\left(21^{\circ} \mathrm{S}\right.$, $56^{\circ}$ E), Atmos. Chem. Phys., 7, 4733-4749, doi:10.5194/acp-74733-2007, 2007.

Tsang, L., Kong, J. A., and Shin, R. T.: Theory of Microwave Remote Sensing, John Wiley, New York, 1985.

van de Hulst, H. C.: Light Scattering by Small Particles, Dover, 1981.

Vermote, E. F., Tanré, D., Deuzé, J. L., Herman, M., and Mocrette, J.-J.: Second simulation of the satellite signal in the solar spectrum, 6S: and overview, IEEE T. Geosci. Remote Sens., 35, 675686, 1997.

Wahner, A., Tyndall, G. S., and Ravishankara, A. R.: Absorption cross sections for symmetric chlorine dioxide as a function of temperature in the wavelength range $240-480 \mathrm{~nm}$, J. Phys. Chem., 91, 2734-2738, 1987.

Wahner, A., Ravishankara, A. R., Sander, S. P., and Friedl, R. R.: Absorption cross-section of $\mathrm{BrO}$ between 312 and $385 \mathrm{~nm}$ at 298 and $223 \mathrm{~K}$, Chem. Phys. Lett., 152, 507-512, 1988.

Wandji Nyamsi, W., Arola, A., Blanc, P., Lindfors, A. V., Cesnulyte, V., Pitkänen, M. R. A., and Wald, L.: Technical Note: A novel parameterization of the transmissivity due to ozone absorption in the k-distribution method and correlated-k approximation of Kato et al. (1999) over the UV band, Atmos. Chem. Phys., 15, 7449-7456, doi:10.5194/acp-15-7449-2015, 2015.

Wanner, W., Strahler, A., Hu, B., Lewis, P., Muller, J.-P., Li, X., Barker Schaaf, C., and Barnsley, M.: Global retrieval of bidirectional reflectance and albedo over land from EOS MODIS and MISR data: Theory and algorithm, J. Geophys. Res., 102, 17143 17161, 1997.

Warren, S. G.: Optical constants of ice from the ultraviolet to the microwave, Appl. Optics, 23, 1206-1225, 1984.

Weinzierl, B., Sauer, D., Minikin, A., Reitebuch, O., Dahlkoetter, F., Mayer, B., Emde, C., Tegen, I., Gasteiger, J., Petzold, A., Veira, A., Kueppers, U., and Schumann, U.: On the visibility of airborne volcanic ash and mineral dust from the pilot's perspective in flight, Phys. Chem. Earth, 45-46, 87-102, doi:10.1016/j.pce.2012.04.003, 2012.

Wiscombe, W.: Improved Mie scattering algorithms, Appl. Optics, 19, 1505-1509, 1980.

WMO: Atmospheric Ozone 1985, Tech. rep., WMO Report No. 16, 1986.

Wyser, K.: The effective radius in ice clouds, J. Climate, 11, 1793 1802, 1998.

Yang, P., Wei, H., Huang, H.-L., Baum, B. A., Hu, Y. X., Kattawar, G. W., Mishchenko, M. I., and Fu, Q.: Scattering and absorption property database for nonspherical ice particles in the near- through far-infrared spectral region, Appl. Optics, 44, 5512-5523, 2005. 
Yang, P., Bi, L., Baum, B. A., Liou, K.-N., Kattawar, G., and Mishchenko, M.: Spectrally consistent scattering, absorption, and polarization properties of atmospheric ice crystals at wavelengths from $0.2 \mu \mathrm{m}$ to $100 \mu \mathrm{m}$, J. Atmos. Sci., 70, 330-347, 2013.

Yoshino, K., Cheung, A. S.-C., Esmond, J. R., Parkinson, W. H., Freeman, D. E., Guberman, S. L., Jenouvrier, A., Coquart, B., and Merienne, M. F.: Improved absorption cross sections of oxygen in the wavelength region 205-240 nm of the Herzberg continuum, Planet. Space Sci., 36, 1469-1475, 1988.

Yoshino, K., Esmond, J. R., Sun, Y., Parkinson, W. H., Ito, K., and Matsui, T.: Absorption cross section measurements of carbon dioxide in the wavelength region $118.7-175.5 \mathrm{~nm}$ and the temperature dependence, J. Quant. Spectrosc. Ra., 55, 53-60, 1996.
Yoshino, K., Parkinson, W. H., Ito, K., and Matsui, T.: Absolute absorption cross-section measurements of Schumann-Runge continuum of $\mathrm{O}_{2}$ at 90 and $295 \mathrm{~K}$, J. Mol. Spectrosc., 229, 238-243, 2005.

Zdunkowski, W., Trautmann, T., and Bott, A. (Eds.): Radiation in the Atmosphere, Cambridge U. Press, Cambridge, UK, 2007.

Zinner, T., Wind, G., Platnick, S., and Ackerman, A. S.: Testing remote sensing on artificial observations: impact of drizzle and 3-D cloud structure on effective radius retrievals, Atmos. Chem. Phys., 10, 9535-9549, doi:10.5194/acp-10-9535-2010, 2010. 